\title{
HeterogeneidAd de LA Vegetación EN AMBIENTES BAsÁlticos deL CENTRO de Argentina
}

\author{
JUAN JOSÉ CANTERO'1-2, JOSÉ MULKO1, CÉSAR NÚÑEZ1, SEBASTIÁN R. ZEBALLOS²-3*, \\ JORGE A. SFRAGULLA ${ }^{3}$, ANDREA AMUCHASTEGUI ${ }^{1}$, GLORIA E. BARBOZA², FRANCO \\ CHIARINI ${ }^{2}$, LUIS ARIZA ESPINAR ${ }^{3}$, ALDO A. BONALUMI ${ }^{4}$, PABLO BRANDOLIN $^{1} \mathrm{y}$ \\ MARCELO CABIDO²
}

\begin{abstract}
Summary: Heterogenity of the vegetation of basaltic environments in central Argentina. The flora and the vegetation of basaltic outcrops of Los Cóndores Mountains, central Argentina, are described. Plant communities were sampled following the Braun-Blanquet methods. The 98 relevés $\times 272$ species matrix was classified through the ISOPAM method. The classification discriminated three main communities occurring in the three different substrates explored in this landscape: Rocky Islands (inselbergs), a Natural Matrix surrounding the Islands and an Agricultural Matrix, surrounding the whole basaltic area. The three communities differed in composition and physiognomy: the Islands were the less disturbed sites, reporting the highest plant species richness and diversity as well as the higher number of endemics, and the lowest number of exotic species. In the other extreme of the disturbance gradient, the Agricultural Matrix showed the opposite patterns and is dominated by annual and perennial herbs, mainly weeds. While the number of aliens is low in the Islands and in the Natural Matrix, almost $50 \%$ of the species are exotic in the Agricultural Matrix. The results of this study reveal that the basaltic inselbergs are relevant sites for the conservation of the natural heritage.
\end{abstract}

Key words: Basaltic environments, flora, plant communities, central Argentina.

Resumen: Se decribe la flora y la vegetación de pasiajes basálticos de la Sierra de Los Cóndores, Córdoba, Argentina. La vegetación se estudió según criterios de la escuela de Braun-Blanquet; la matriz de 98 inventarios $\times 272 \mathrm{spp}$. fue clasificada a través del método ISOPAM. El análisis discrimina tres comunidades correspondientes respectivamente a las tres geoformas relevadas en estos paisajes: Islas rocosas (inselbergs), la Matriz Natural que rodea a las Islas y la Matriz Agrícola que circunda al complejo de paisajes basálticos. Las tres comunidades difieren en su composición florística: las Islas rocosas son los sitios menos perturbados, más ricos en especies, con mayor diversidad, mayor número de especies endémicas y su fisonomía está dominada por formas arbustivas. En el otro extremo, la Matriz Agrícola es la más pobre en especies, la de menor diversidad y endemicidad, y predominan las hierbas perennes y anuales. Las Islas rocosas y la Matriz Natural registran bajos números de especies exóticas en su composición, mientras cerca del $50 \%$ de la flora de la matriz agrícola se compone de especies adventicias. Los resultados de este estudio revelan la importancia de las islas rocosas basálticas para la conservación del patrimonio natural de la provincia de Córdoba.

Palabras clave: Ambientes basálticos, flora, comunidades vegetales, centro de Argentina.

\footnotetext{
1 Departamento de Biología Agrícola, Facultad de Agronomía y Veterinaria, UNRC, Ruta Nac. 36, Km. 601, C. P. X5804BYA, Río Cuarto, Córdoba.

${ }^{2}$ Instituto Multidisciplinario de Biología Vegetal (CONICET-UNC), Av. Vélez Sársfield 1611, CC 495, X5000HVA, Córdoba.

${ }^{3}$ Facultad de Ciencias Exactas, Físicas y Naturales, UNC. Av. Vélez Sársfield 1611, 5016 Córdoba.

${ }^{4}$ Secretaría de Minería, Provincia de Córdoba, Hipólito Yrigoyen 401, 5000 Córdoba.

*Autor para correspondencia: Sebastián Zeballos, sebazeba@hotmail.com
} 


\section{INTRODUCCIÓN}

Los afloramientos rocosos se reconocen como importantes centros de diversidad y endemismos de plantas en todo el mundo (Smith \& Cleff, 1988; Barthlott et al., 1993; Alves \& Kolbek, 1994; Porembski et al., 1994; Michelangeli, 2000; Burke et al., 2003; Giuletti et al., 2005; Jacobi \& Carmo, 2008a, b), debido a que frecuentemente están asociados a comunidades exclusivas (Porembsky et al., 1996; Pozo et al., 2013). Los hábitats rocosos suelen actuar como refugio (sensu Birks, 2015) de plantas, dando protección a especies raras y endémicas (Porembski et al., 1996; Jacobi et al., 2007), como así también a especies sensibles al fuego (Clarke, 2002; Watson \& Wardell-Johnson, 2004), al pastoreo (Milchunas \& Noy-Meir, 2002) y a sequías (Burke, 2002). Al mismo tiempo, se trata de ambientes sometidos a perturbaciones por actividades mineras, especialmente en el caso de rocas ricas en minerales metalíferos (Finger et al., 1999), lo cual provoca severos impactos en la estructuctura y composición de las comunidades vegetales (Ginocchio \& Baker, 2004; Brady et al., 2005; Jacobi \& do Carmo, 2008a; Gibson et al., 2010; Jacobi et al., 2011). Distintos autores han reportado, además, la susceptibilidad de los ambientes rocosos a la invasión por especies exóticas, especialmente en sistemas tropicales sometidos a deforestación, incendios y ganadería (Porembski, 2000; Gomes \& Alves, 2009, 2010).

En el centro de Argentina, los afloramientos rocosos constituyen los geosistemas más antiguos dentro de una matriz generalmente muy modificada por distintas perturbaciones (Cantero et al., 2016). $\mathrm{Su}$ origen se remonta al Cretácico SuperiorTerciario Inferior; como respuesta a fenómenos distensivos que afectaron a la placa Sudamericana, se produjo en la provincia de Córdoba (Sierra Chica) un magmatismo compuesto por rocas basálticas alcalinas asociadas a depósitos sedimentarios continentales (Gordillo \& Lencinas, 1979; Llambías \& Brogioni, 1981; Kay \& Ramos, 1996; Lagorio, 1998, 2008). Una consecuencia de esos fenómenos es la presencia de cerros basálticos aislados, a modo de inselbergs o islas rocosas, con relieve cónico o en forma de mesadas que se elevan sobre las planicies circundantes; estas planicies están conformadas de material loéssico y su vegetación natural ha sido reemplazada por cultivos. Además, las mesadas y los conos son, en general, poco accesibles al ganado doméstico y al ingreso del fuego, proveyendo de hábitats singulares para la flora y fauna nativa, lo que las convierte en áreas prioritarias para la conservación.

Recientemente Cantero et al. (2016) han explorado la variabilidad florística a escala regional de afloramientos basálticos en provincias del centro de Argentina (Santiago del Estero, La Rioja, San Luis y Córdoba), estableciendo relaciones estrechas entre los cambios en composición y el clima. Sin embargo, la variabilidad florística de los paisajes basálticos a escala local permanece inexplorada. Este tipo de información adquiere gran relevancia debido a que estos afloramientos actualmente están sometidos al aprovechamiento minero de sus rocas (Cantero et al., 2016): aproximadamente $50.000 \mathrm{t} / \mathrm{mes}$ de basaltos alcalinos y nefelinitas olivínicas se explotan y procesan empleándoselas en la industria de la construcción en diversas aplicaciones (Bonalumi et al., 2014). Los afloramientos basálticos remanentes son foco de atención de futuras explotaciones y esto anticipa la ocurrencia de un típico y grave conflicto entre la conservación y la apropiación de servicios ecosistémicos (Cáceres et al., 2015).

La caracterización de la heterogeneidad florística de estos geosistemas constituye indudablemente un aporte científico imprescindible para poder dar sustento a una agenda destinada a evitar la pérdida de estos ecosistemas por efectos antrópicos, aspectos largamente reclamados desde espacios académicos y gubernamentales (Rezende, 2013; Conceição et al., 2015; Díaz et al., 2015). Por lo tanto, en este trabajo se describe la flora vascular, los espectros biológicos y las comunidades vegetales de los afloramientos basálticos de la Sierra de Los Cóndores en la provincia de Córdoba, Argentina central. Específicamente, en esta contribución pretendemos responder: 1) ¿Cual es la composición florística de las comunidades vegetales en los diferentes ambientes de los afloramientos basálticos?; 2) ¿Cómo se asocian las comunidades vegetales con los diferentes ambientes?; 3) ¿Difieren esos ambientes en la riqueza y diversidad de especies, en su endemicidad y en sus espectros de formas de vida? y 4) ¿Cuál es la importancia relativa de distintos corotipos y de las especies nativas y exóticas en la composición de las diferentes comunidades? 


\section{J. J. Cantero et al. - Heterogeneidad de la vegetación en ambientes basálticos}

\section{Materiales y Método}

Área de Estudio. El área de estudio comprendió afloramientos basálticos, con forma de mesadas y conos, ubicados en la Sierra de Los Cóndores (provincia de Córdoba, centro de Argentina), entre 700-760 m s.n.m. (Fig. 1). En el área de estudio la precipitación media anual es de $686 \mathrm{~mm}$, con más del $50 \%$ de las lluvias concentradas en la estación más cálida; la temperatura media anual es de $15.9^{\circ} \mathrm{C}$ (Hijmans et al., 2005; www.worldclim. org). De acuerdo al esquema fitogeográfico de Cabrera (1976), la vegetación del territorio donde están emplazados los afloramientos estudiados corresponde al Distrito Chaqueño Serrano.

Esta sierra constituye el extremo austral de la Sierra Chica de Córdoba y está constituida por un complejo volcánico-sedimentario que alcanza aproximadamente $250 \mathrm{~m}$ de espesor y apoya en discordancia angular sobre el basamento (Lagorio et al., 2014). Gordillo \& Lencinas (1967) definieron en el norte de la sierra el Grupo Sierra de los Cóndores, integrado por una unidad basal sedimentaria (Formación Embalse Río Tercero) a la que siguen dos ciclos volcánicos (Volcanitas Cerro Colorado y Volcanitas Rumipalla), separados por una intercalación sedimentaria (Conglomerado Cerro Libertad). Los niveles lávicos son macizos, negros a pardo oscuros, registrándose coladas pardo rojizas con numerosas amígdalas conformadas por ceolitas granulares y carbonato. Dataciones K/ Ar (Lagorio et al., 2014 y bibliografía allí citada) señalan que las lavas de la Sierra de Los Cóndores fueron extruídas en el lapso 133-115 Ma (Cretácico Inferior).

Se estudiaron dos grupos de mesadas de volcanitas (en adelante Islas rocosas, I) (Fig. 1). Uno de ellos está ubicado al sur de la Sierra de Los Cóndores (cerros Corona, Alto de Maldonado y otros aledaños), y se compone de latibasaltos (Lagorio et al., 2014). El otro grupo se dispone hacia el oeste de la Sierra de los Cóndores, y consiste en un conjunto de mesadas (cerro Malo $\mathrm{y}$ adyacentes), compuestas por traquiandesitas y traquibasaltos. Por su quimismo, las rocas de los cerros Corona y aledaños pertenecen a la suite basalto transicional-latibasalto (BTL), mientras que en el cerro Malo las rocas pertenecen a la suite alcalina (BA), ambas definidas por Lagorio (2008). Las rocas de BTL tienen valores de $\mathrm{SiO}_{2}$ más elevados (52.7-55\%) en relación a BA (49.3$51.6 \%$ ). En cuanto al contenido de $\mathrm{MgO}$, también es mayor en la serie BTL (7.08-8.98\%) mientras que en las rocas de BA oscila entre 3.84-5.82\%. Respecto al $\mathrm{K}_{2} \mathrm{O}$, su concentración es mayor en BA (4.34-4.36\%) en relación a las rocas de BTL (2.99-3.60\%) (Lagorio, 2008 y análisis propios). La vegetación rupícola domina exclusivamente estas mesadas, con abundantes parches de bromeliáceas, matorrales y pastizales como las fisonomías más importantes.

Entre los dos grupos de mesadas y conos de basaltos mencionados se encuentra una planicie fuertemente ondulada, con más del $5 \%$ de pendiente, constituida por una capa de conglomerados (en adelante Matriz Natural, MN), con abundante presencia de clastos provenientes de la destrucción de los basaltos de las volcanitas de las islas (Conglomerado Cerro Libertad) (Gordillo \& Lencinas, 1967). Un mosaico de bosques bajos y matorrales xerófilos caracteriza la vegetación dominante de esta planicie ondulada. Toda el área está sometida a pastoreo con ganado doméstico con una presión de carga animal de aproximadamente 1.5 EV. ha ${ }^{-1}$; los incendios de carácter intencional o accidental han afectado a esta planicie ondulada al menos durante tres oportunidades en los últimos 15 años (Obervación personal de los autores y pobladores de la region).

Hacia el oeste del último relieve se extiende una planicie suavemente ondulada (en adelante Matriz Agrícola, MA) con menos del 3\% de pendiente, conformada por sedimentos fluvioeólicos pertenecientes al Pleistoceno Medio y Superior (Cantú, 1992; Carignano, 1997; Bonalumi et al., 2005). Los sedimentos están constituidos por loess, limos, limos arenosos, masivos a débilmente laminados, con elevados porcentajes de arcillas y vidrio volcánico en su fracción clástica, e intercalaciones de arenas finas a medias y abundantes concreciones calcáreas. Esta planicie tuvo originalmente la misma estructura de vegetación que la planicie ondulada pero fue profundamente modificada hace más de 50 años a través del reemplazo de la vegetación natural por cultivos. En la actualidad, además de las especies sembradas (principalmente oleaginosas de grano), aparecen asociadas especies nativas y exóticas a las que se considera como malezas. En la Fig. 2 y 3 se observan detalles de las tres geoformas estudiadas. 
Bol. Soc. Argent. Bot. 52 (1) 2017
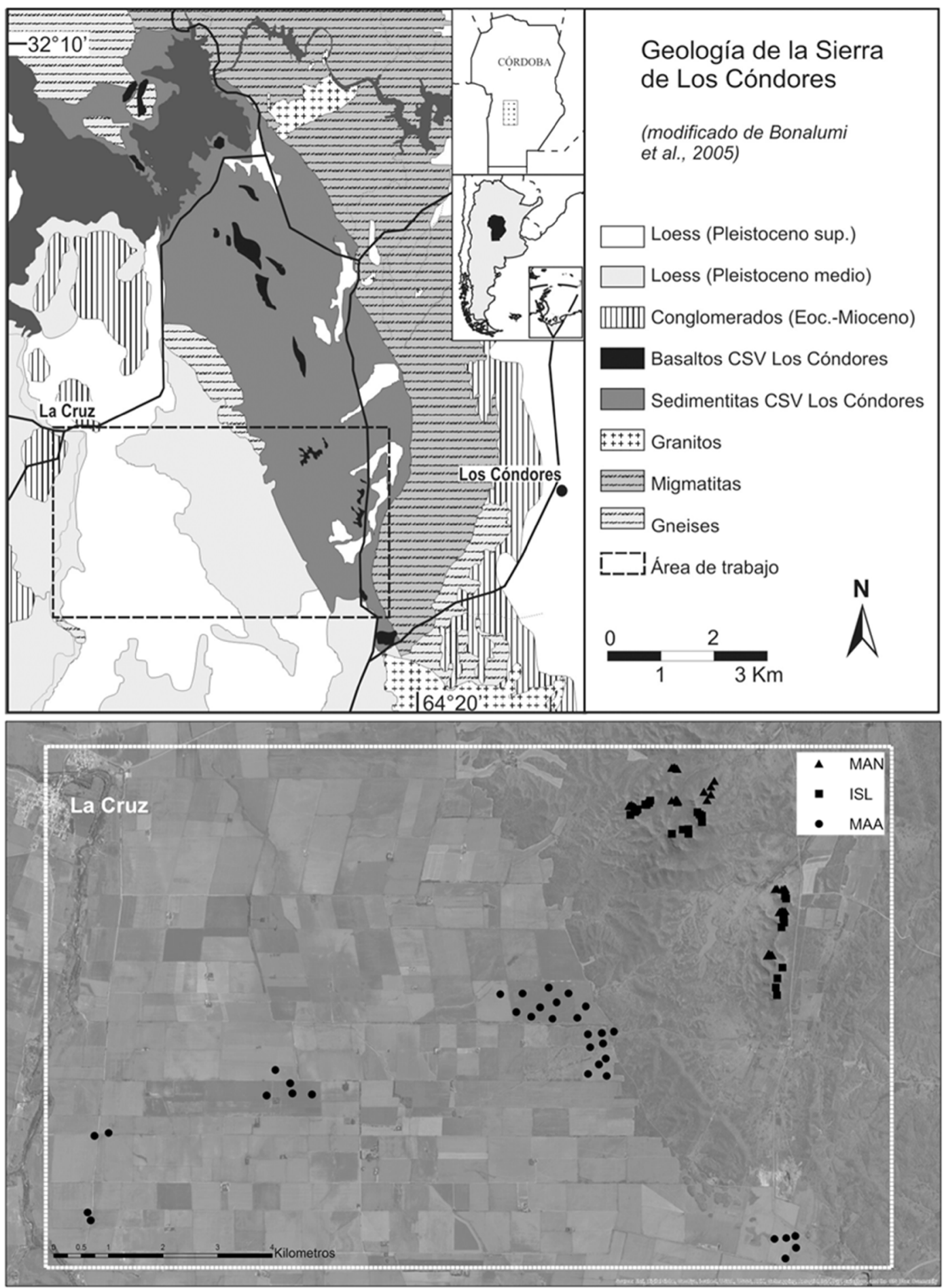

Fig. 1. Ubicación del la Sierra de Los Cóndores en la República Argentina y en la Provincia de Córdoba. En la parte superior de la figura se observan las principales características geológicas del área de estudio, mientras en el detalle de la porción inferior se aprecia la distribución de los sitios de muestreo en las tres geoformas analizadas. MAN, Matriz Natural; ISL, Isla rocosa; y MAA, Matriz agrícola. 
A

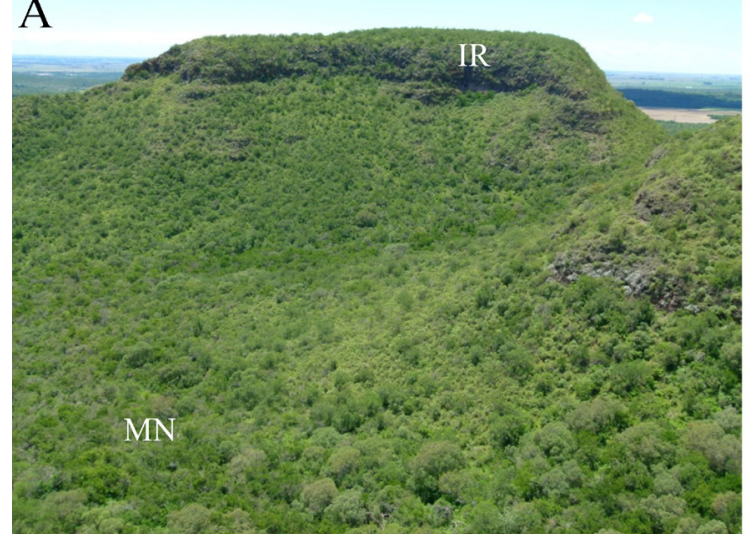

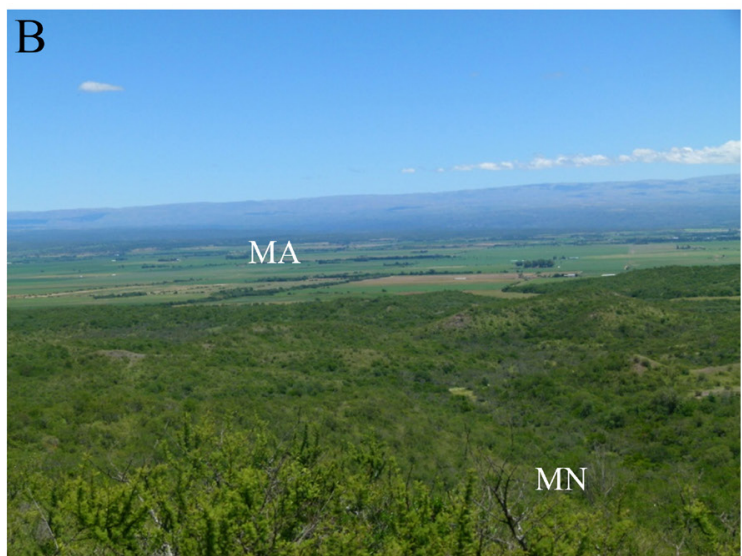

Fig. 2. Superficies geomorfológicas de la Sierra de Los Cóndores (Córdoba, Argentina) estudiadas en este trabajo. A: Isla rocosa (IR); B: al frente se observa la Matriz Natural (MN) y al fondo, la Matriz agrícola (MA).

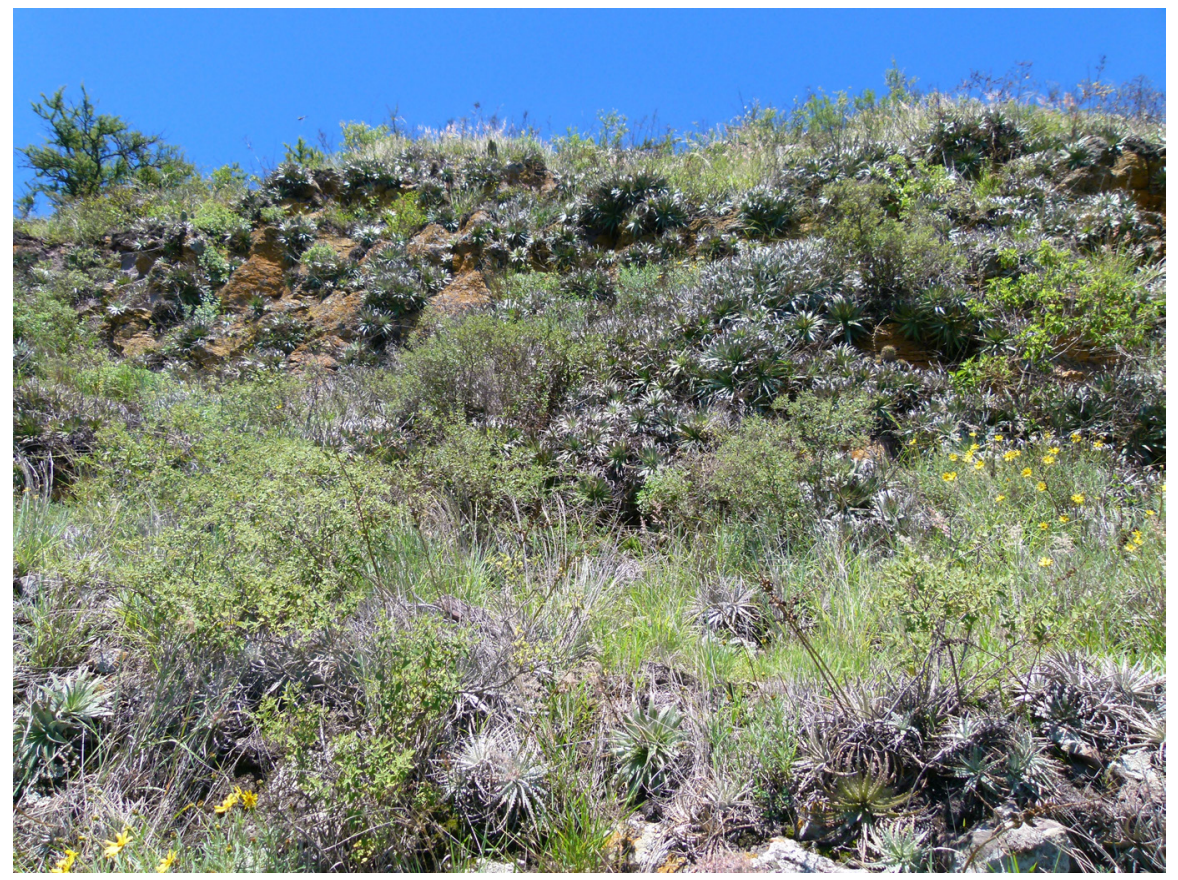

Fig. 3. Aspecto de una facie de la comunidad sobre las mesadas basálticas (i.e., Islas rocosas) dominada por Dyckia floribunda en la Sierra de Los Cóndores, provincia de Córdoba.

Relevamiento de la flora y la vegetación. La vegetación se relevó en las tres superficies geomorfológicas descriptas en la sección anterior: Islas rocosas (I), Matriz Natural (MN), circundante a las I, y Matriz Agrícola (MA) adyacente a MN (Figs. 1, 2, 3). Se seleccionaron 7 sitios en cada superficie geomorfológica, abarcando la variabilidad local de cada hábitat. Para el caso de las Islas rocosas, cada sitio comprendió una mesada (afloramiento) diferente. Debido a las dificultades que tienen los estudios fitosociológicos de la vegetación rupícola, en este trabajo se siguió 
la propuesta metodológica de Ortiz \& Rodríguez Oubiña (1993), considerando a cada mesada como un stand, compuesto por un conjunto de biotopos (grietas, fisuras, diaclasas, etc.; Fig. 3). Las 7 mesadas estudiadas presentan una forma cónica a sub-cónica y los censos de la vegetación se realizaron en su cima o plateau (Fig. 2). Como los límites de los afloramientos fueron definidos según criterios geomorfológicos y topográficos, los stands muestreados difirieron en forma y tamaño. En cada sitio se localizaron cuatro cuadrados independientes de $5 \times 5 \mathrm{~m}$, en espacios uniformes en cuanto a la fisonomía, composición florística de la vegetación y condiciones ecológicas.

Para el caso de las MN, los 7 sitios de relevamientos intensivos se localizaron en la periferia de las Islas rocosas (Fig. 1), mientras que para la MA, los sitios se ubicaron de la siguiente manera: cuatro en el límite con la MN y los otros tres alejados hasta una distancia de aproximadamente $12 \mathrm{~km}$ respecto a la $\mathrm{MN}$ (Fig. 1). El criterio de uniformidad-homogeneidad para la selección de los sitios en MN fue similar al empleado en I, evitando áreas con alto grado de perturbación (i.e., fuego y sobrepastoreo).

Los relevamientos se llevaron a cabo en los meses de diciembre de 2014 y marzo 2015, período en el cual la mayoría de las especies presentan estructuras reproductivas que permiten su identificación. En cada cuadrado se registraron todas las especies de plantas vasculares presentes y se estimó su abundancia-cobertura según la escala combinada de Braun-Blanquet (1979). Un total de 98 censos fueron realizados en las tres superficies geomorfológicas (28 en I, 35 en MN y 35 en MA). Las especies endémicas presentes en los relevamientos fueron divididas en tres grupos: 1) endémicas locales, que se presentan exclusivamente en la provincia de Córdoba; 2) endémicas regionales, que crecen en la provincia de Córdoba y en provincias limítrofes o vecinas a Córdoba; y 3) endémicas nacionales, especies que tienen una amplia distribución dentro del territorio de Argentina. Para establecer el rango de distribución de los endemismos se emplearon los trabajos de Zuloaga et al. (1994), Cabido et al. (1998), Zuloaga \& Morrone (1999a, b), Zuloaga et al. (2008) y Chiapella \& Demaio (2015). Para determinar la pertenencia de las especies a diferentes corotipos se siguió el criterio de Cabido et al. (1998). Las especies incluidas en los inventarios fueron clasificadas en formas de vida según Giorgis et al. (2011): Árboles, Arbustos, Arbustos Parásitos, Bromeliáceas, Cactáceas Columnares, Cactáceas Globulares, Cactáceas Opuntioides, Enredaderas, Epífitas, Gramíneas, Graminoides, Gramíneas en Mata, Hierbas Anuales, Helechos, Hierbas Perennes Caducifolias, Hierbas Perennes Siempre verdes y Parásitas. La nomenclatura de las especies sigue al Catálogo de las Plantas Vasculares del Cono Sur (Zuloaga et al., 2008) y su actualización online (http://www.darwin.edu.ar/). Todas las especies registradas en los inventarios fueron coleccionadas y sus ejemplares fueron depositados en los herbarios del Museo Botánico de Córdoba, Universidad Nacional de Córdoba (CORD) y de la Universidad Nacional de Río Cuarto (RIOC).

Análisis de los datos. La matriz de 272 spp. $\times$ 98 inventarios fue clasificada a través del método ISOPAM (Schmidtlein et al., 2010). Este método es recomendado para datos de vegetación heterogéneos y representa una "aproximación de fuerza bruta" ("bruteforce approach" en el sentido de Schmidtlein et al. (2010), por su denominación en inglés), a la clasificación de la vegetación, ya que busca iterativamente la partición de la base de datos original, maximizando la fidelidad de las especies a los grupos resultantes. El método jerárquico ISOPAM se corrió sobre una matriz de disimilitud de BrayCurtis. Con el propósito de visualizar el resultado de la clasificación, se ordenó la misma matriz de datos de vegetación a través del método ISOMAP (por sus siglas en Inglés "isometric feature mapping") (Tenenbaum et al., 2000), que forma la base del método ISOPAM (Scmidtlein et al., 2010). Con la finalidad de aproximarnos a una clasificación lo más fiel posible, se seleccionó como el valor óptimo al primer nivel jerárquico durante la clasifación ISOPAM (Černý et al., 2015). Antes de ejecutar estos análisis, los datos de abundancia-cobertura de las especies según Braun-Blanquet fueron modificados de acuerdo a la conversión propuesta por van der Maarel (1979). Para el análisis de clasificación de la vegetación ISOPAM y la visualización de la misma a través de ISOMAP, se utilizó el paquete vegan (v 2.0-7, http://CRAN.R-project.org/package=vegan) e isopam (v 0.9-12, Schmidtlein et al., 2010), ambos se corrieron en R (R Development Core Team, 2014). 


\section{J. J. Cantero et al. - Heterogeneidad de la vegetación en ambientes basálticos}

A partir de los resultados obtenidos a través del método ISOPAM (tres grupos principales de inventarios correspondientes a las tres superficies geomorfológicas relevadas), se calcularon los siguientes atributos de la vegetación para cada uno de esos grupos: riqueza, diversidad (ShannonWiener), equitatividad y dominancia, siguiendo la propuesta de McCune \& Mefford (1999). Para evaluar si hubo diferencias significativas en esos atributos entre los grupos de inventarios, se realizó un ANOVA con los censos agrupados por sitios (las tres superficies geomorfológicas), y se utilizó el test de Tuckey para establecer la significancia estadística. Previamente los datos fueron analizados para comprobar la normalidad y homogeneidad de varianza. Estos análisis se realizaron usando el programa InfoStat (Di Rienzo et al., 2011).

\section{Resultados}

Características florísticas de las islas rocosas y sus ambientes circundantes

La flora vascular registrada en los inventarios de las tres superficies geomorfológicas relevadas está constituida por $272 \mathrm{spp}$. distribuidas en 67 familias y 197 géneros (Ver Apéndice en versión online). Las familias más numerosas fueron: Poaceae (16.48\%), Asteraceae (15.75\%), Malvaceae (5.49\%), Solanaceae (4.46\%), Fabaceae $(4.03 \%)$ y Verbenaceae $(4.03 \%)$. Muchas familias estuvieron pobremente representadas; hay 34 familias con un único género y una sola especie. Los géneros mejor representados fueron: Baccharis (6 spp.), Nassella (5 spp.), Glandularia (5 spp.) y Solanum (5 spp.) (Ver Apéndice en versión online). El clado mejor representado en los tres hábitats fue el de las Astéridas con 103 spp., seguido por el de las Rósidas con 66 spp. El 50.55\% de las especies registradas pertenece a sólo 6 familias. Los tres tipos de hábitats estudiados tuvieron una representación diferencial en las familias más numerosas de plantas vasculares del elenco total registrado, con un patrón coincidente entre I y $\mathrm{MN}$, mientras que en MA sólo Asteraceae y Poaceae mantuvieron la importancia exhibida en los otros dos ambientes. Las especies exclusivas de cada hábitat fueron 73 en I, 28 en MN y 33 en MA (Apéndice). Sólo 12 spp. fueron comunes a los tres hábitats y se las halló en promedio en el $81.63 \%$ del total de los 98 censos:
Acacia caven, Bidens subalternans, Chenopodium album, Clematis montevidensis, Commelina erecta, Dichondra sericea, Eragrostis lugens, Evolvulus sericeus, Galium richardianum, Oxalis conorrhiza, Schinus fasciculatus y Talinum paniculatum.

\section{Patrones comunitarios en los ambientes basálticos}

Los resultados de la clasificación a través de ISOPAM están resumidos en la Tabla 1. La matriz de inventarios $\times$ especies fue dividida en tres grupos principales y en 7 sub-grupos. El primer nivel de división es coincidente con las tres unidades geomorfológicas relevadas (I, MN y MA), mientras los subgrupos corresponden a variaciones internas de las mismas. La Fig. 4 muestra en el plano de ordenación los grupos y subgrupos resultantes de la clasificación.

\section{Grupo 1. Flourensia campestris - Kageneckia lanceolata}

Este grupo de inventarios corresponde a las mesadas y conos, representando a las verdaderas comunidades rupícolas sobre estos ambientes basálticos. Fisonómicamente, se trata de matorrales bajos cerrados dominados alternativamente por Acacia caven y Aloysia gratissima, junto a las especies que dan el nombre al grupo. Un complejo de especies saxícolas (por ej., Achyrocline alatum, Acmella decumbens, Buddleja cordobensis, Flourensia campestris, Monnina dictyocarpa, Mostacillastrum stenophyllum, Wedelia buphtalmiflora y Zornia trachycarpa) y otras casmofíticas (por ej., Argyrochosma nivea, Cheilanthes micropteris, Cheilanthes myriophylla, Cordobia argentea, Deuterocohnia longipetala, Dyckia floribunda, Gymnocalycium calochlorum y Pleopeltis pinnatifida) fueron exclusivas de las islas. Algo similar ocurrió con especies medicinales de alta demanda regional e intensamente cosechadas (por ej., Achyrocline satureioides y Mintostachys verticillata) como con gramíneas palatables, muy preferidas por el ganado doméstico (por ej., Briza maxima, Bromus auleticus, Eustachys distichophylla, Nassella hyalina, Nassella neesiana y Poa ligularis). Pueden reconocerse dos subgrupos dentro de esta unidad (Tabla 1, Fig. 3). El primer sub-grupo (1.1 en la Tabla 1) comprende un número importante de especies diagnósticas, sobresaliendo la Bromeliácea casmófita Dyckia floribunda (Fig. 3) y Flourensia campestris como 


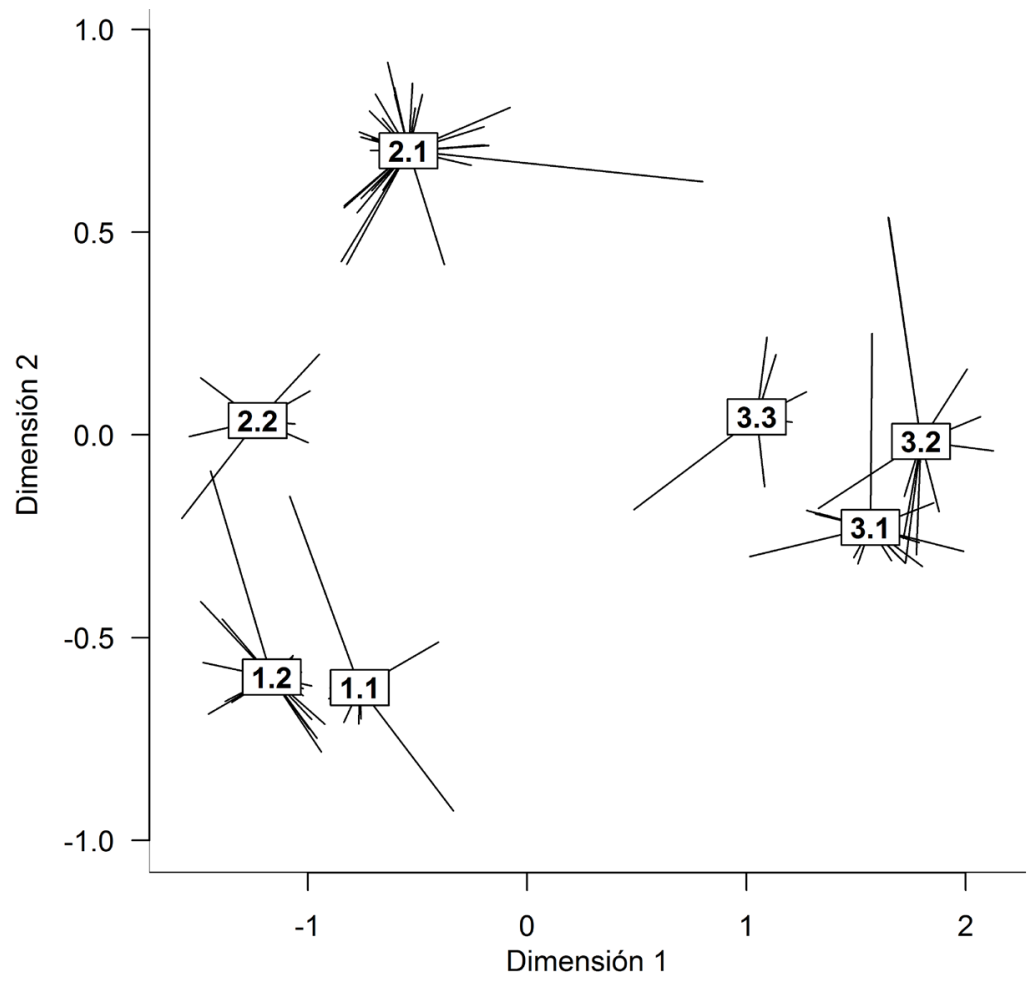

Fig. 4. Clasificación de la vegetación de ambientes basálticos de la Sierra de Los Cóndores, Córdoba, visualizada a través del diagrama de ordenación de ISOMAP. Los grupos y subgrupos están diferenciados a través de su código numérico en el centroide multivariado de cada grupo. Para identificar los grupos dirigirse a la Tabla 1.

uno de los arbustos dominantes. El segundo subgrupo (1.2 en la Tabla 1) incluye inventarios en los cuales Kageneckia lanceolata aparece como la especie dominante y, al mismo tiempo, uno de los taxones diagnósticos con máxima constancia y alta cobertura; exhibe también un número importante de especies diagnósticas (Tabla 1), aunque comparte buena parte de su elenco florístico con el sub-grupo anterior.

\section{Grupo 2. Aristida mendocina - Setaria leucopila}

Este grupo de inventarios corresponde a las planicies onduladas (denominadas aquí Matriz Natural), que, a manera de canchales o coluviones, rodean a las mesadas y conos, diferenciandose claramente de estas últimas por la acumulación de derrubios en superficie. Aquí predominan especies glareícolas o glerícolas, es decir aquellas que se caracterizan por vivir sobre sustratos pedregosos sueltos a diferencia de las especies rupícolas que son típicas de los conos y mesadas. Fisonómicamente, se trata de un mosaico de pastizales y bosques bajos, cerrados, dominados alternativamente por arbustos como Acacia caven y Aloysia gratissima $\mathrm{y}$ por los pastos Bothriochloa barbinodis y Heterosperma ovatifolium, junto a las especies que dan el nombre al grupo. En MN aparecen como exclusivas especies de gramíneas poco preferidas por los herbivoros domésticos (por ej., Aristida mendocina y Cenchrus myosuroides) y también especies anuales nativas, de aparición frecuente en condiciones de sobrepastoreo (por ej., Heterosperma tenuisectum, Schkuhria pinnata y Xanthium spinosum). Pueden reconocerse dos sub-grupos dentro de esta unidad (Tabla 1, Fig. 2). El sub-grupo 2.1 comprende especies diagnósticas que son a su vez taxones nativos que incrementan notablemente su abundancia y cobertura bajo perturbaciones como el fuego y pastoreo, destacándose en ese sentido Parthenium hysterophorus, Tagetes minuta 
Tabla 1. Tabla sinóptica de la vegetación de paisajes basálticos de la Sierra de Los Cóndores, Córdoba, Argentina. Se incluyen porcentajes de constancia y valores medios de cobertura de las especies. Las especies se disponen según su carácter diagnóstico establecido a través del análisis ISOPAM. Las especies diagnósticas de los diferentes grupos discriminados por el análisis se muestran en negrita; sólo se han incluido en los grupos de especies diagnósticas a taxones con valores de constancia del $25 \%$ o superiores para el grupo del cual son diagnósticas. Geoformas: I= Islas rocosas; MN= Matriz Natural; MA= Matriz Agrícola. Tipos de comunidades: Grupo 1 = Flourensia campestris - Kageneckia lanceolata; 2 = Aristida mendocina - Setaria leucopila; 3 = Digitaria sanginalis - Eleusine indica - Borreria spinosa.

\begin{tabular}{|c|c|c|c|c|c|c|c|}
\hline \multirow{2}{*}{$\begin{array}{l}\text { Geoforma } \\
\text { Grupos y subgrupos }\end{array}$} & \multicolumn{2}{|c|}{1} & \multicolumn{2}{|c|}{$\mathrm{MN}$} & \multicolumn{3}{|c|}{ MA } \\
\hline & 1.1 & 1.2 & 2.1 & 2.2 & 3.1 & 3.2 & 3.3 \\
\hline & 10 & 18 & 29 & 7 & 16 & 12 & 6 \\
\hline \multicolumn{8}{|l|}{ Especies típicamente encontradas en 1.1} \\
\hline Dyckia floribunda Griseb. var. floribunda* & $100^{(1)}$ & $11^{(+)}$ & & & & & \\
\hline Flourensia campestris Griseb.* & $100^{(3)}$ & $56^{(1)}$ & & & & & \\
\hline Tragia geraniifolia Klotzsch ex Baill. & $100^{(1)}$ & $72^{(1)}$ & $28^{(1)}$ & $14^{(+)}$ & & & \\
\hline Lippia integrifolia (Griseb.) Hieron. & $90^{(3)}$ & & $24^{(1)}$ & & & & \\
\hline Melica eremophila Torres & $80^{(1)}$ & $28^{(+)}$ & & & & & \\
\hline Nassella hyalina (Nees) Barkworth & $80^{(1)}$ & $22^{(+)}$ & & & & & \\
\hline Nothoscordum gracile (Dryand. ex Aiton) Stearn var. gracile & $80^{(1)}$ & $11^{(+)}$ & & & & & \\
\hline Pfaffia gnaphaloides (L. f.) Mart. & $80^{(1)}$ & $39^{(+)}$ & $14^{(+)}$ & & & & \\
\hline Spergula ramosa (Cambess.) D. Dietr. ssp. ramosa & $80^{(1)}$ & $6^{(+)}$ & & & & & \\
\hline Stenandrium dulce (Cav.) Nees & $\mathbf{8 0}^{(1)}$ & $28^{(+)}$ & $21^{(+)}$ & & & & \\
\hline Talinum paniculatum (Jacq.) Gaertn. & $80^{(1)}$ & $67^{(1)}$ & $10^{(+)}$ & & & $17^{(+)}$ & \\
\hline Trixis divaricata (Kunth) Spreng. ssp. discolor (D. Don) Katinas* & $80^{(1)}$ & $39^{(+)}$ & $17^{(+)}$ & & & & \\
\hline Buddleja cordobensis Griseb.* & $70^{(1)}$ & $44^{(+)}$ & & & & & \\
\hline Evolvulus sericeus Sw. var. sericeus & $70^{(1)}$ & $17^{(+)}$ & $28^{(+)}$ & & & & \\
\hline Hysterionica jasionoides Willd. & $70^{(+)}$ & $22^{(+)}$ & $7^{(+)}$ & & & & \\
\hline Krapovickasia flavescens (Cav.) Fryxell & $70^{(1)}$ & & $7^{(+)}$ & $14^{(+)}$ & & & \\
\hline $\begin{array}{l}\text { Mostacillastrum stenophyllum (Gillies ex Hook. \& Arn.) O.E. } \\
\text { Schulz }\end{array}$ & $70^{(1)}$ & $6^{(+)}$ & & & & & \\
\hline Oxalis conorrhiza Jacq. & $70^{(+)}$ & $22^{(+)}$ & $7^{(+)}$ & & $19^{(+)}$ & & \\
\hline Rhynchosia bicentrica B.L. Turner & $70^{(+)}$ & $17^{(+)}$ & & & & & \\
\hline Zexmenia buphtalmiflora (Lorentz) Ariza* & $70^{(+)}$ & $44^{(+)}$ & & & & & \\
\hline Croton subpannosus Müll. Arg. ex Griseb. & $60^{(1)}$ & & & $14^{(+)}$ & & & \\
\hline Digitaria californica (Benth.) Henrard var. californica & $60^{(+)}$ & $6^{(+)}$ & & $14^{(+)}$ & & & \\
\hline Monnina dictyocarpa Griseb. & $60^{(+)}$ & $6^{(+)}$ & & & & & \\
\hline $\begin{array}{l}\text { Poa ligularis Nees ex Steud. var. resinulosa (Nees ex Steud.) } \\
\text { Fernández Pepi \& Giussani* }\end{array}$ & $60^{(1)}$ & $11^{(+)}$ & & & & & \\
\hline Proustia cuneifolia D. Don var. mendocina (Phil.) Ariza* & $60^{(1)}$ & $44^{(1)}$ & $3^{(+)}$ & & & & \\
\hline Trichocereus candicans (Gillies ex Salm-Dyck) Britton \& Rose* & $60^{(+)}$ & $22^{(+)}$ & $3^{(+)}$ & & & & \\
\hline Turnera sidoides L. ssp. pinnatifida (Juss. ex Poir.) Arbo & $60^{(1)}$ & & $10^{(+)}$ & & & & \\
\hline Acanthostyles buniifolius (Hook. \& Arn.) R.M. King \& H. Rob. & $5 \mathbf{5}^{(1)}$ & $17^{(+)}$ & $7^{(+)}$ & & & & \\
\hline Ephedra triandra Tul. emend. J.H. Hunz. & $5 \mathbf{0}^{(+)}$ & $6^{(+)}$ & $3^{(+)}$ & $14^{(+)}$ & & & \\
\hline Philibertia gilliesii Hook. \& Arn. & $5 \mathbf{5 0}^{(+)}$ & $17^{(+)}$ & $3^{(+)}$ & & & & \\
\hline Sphaeralcea cordobensis Krapov. ${ }^{\circ}$ & $5 \mathbf{0}^{(+)}$ & $11^{(+)}$ & & & & $8^{(+)}$ & \\
\hline Tillandsia bandensis Baker & $5 \mathbf{5 0}^{(+)}$ & $17^{(+)}$ & $7^{(+)}$ & & & & \\
\hline Tripodanthus flagellaris (Cham. \& Schltdl.) Tiegh. & $5 \mathbf{5}^{(+)}$ & $6^{(+)}$ & & & & & \\
\hline Bromus auleticus Trin. ex Nees & $5 \mathbf{5}^{(1)}$ & & & & & & \\
\hline Dyschoriste humilis Lindau & $50^{(+)}$ & & & & & & \\
\hline Cucurbitella asperata (Gillies ex Hook. \& Arn.) Walp. & $40^{(+)}$ & $11^{(+)}$ & & & & & \\
\hline Melica argyrea Hack. & $40^{(+)}$ & & & & & & \\
\hline Petunia axillaris (Lam.) Britton, Stern \& Poggenb. ssp. axillaris & $40^{(+)}$ & $6^{(+)}$ & & & & & \\
\hline
\end{tabular}


Bol. Soc. Argent. Bot. 52 (1) 2017

\begin{tabular}{|c|c|c|c|c|c|c|c|}
\hline \multirow{2}{*}{$\begin{array}{l}\text { Geoforma } \\
\text { Grupos y subgrupos }\end{array}$} & \multicolumn{2}{|c|}{ I } & \multicolumn{2}{|c|}{ MN } & \multicolumn{3}{|c|}{ MA } \\
\hline & 1.1 & 1.2 & 2.1 & 2.2 & 3.1 & 3.2 & 3.3 \\
\hline$N^{\circ}$ Censos & 10 & 18 & 29 & 7 & 16 & 12 & 6 \\
\hline Cordobia argentea (Griseb.) Nied. & $30^{(1)}$ & & & & & & \\
\hline Paronychia brasiliana DC. var. brasiliana & $30^{(+)}$ & & & & & & \\
\hline Solanum elaeagnifolium Cav. & $30^{(+)}$ & & & & & & \\
\hline \multicolumn{8}{|l|}{ Especies típicamente encontradas en 1.2} \\
\hline Kageneckia lanceolata Ruiz \& Pav & $10^{(2)}$ & $100^{(4)}$ & & $43^{(4)}$ & & & \\
\hline Croton lachnostachyus Baill. & $30^{(1)}$ & $\mathbf{9 4}^{(2)}$ & $21^{(+)}$ & $100^{(1)}$ & & & \\
\hline Lorentzianthus viscidus (Hook. \& Arn.) R.M. King \& H. Rob. & $40^{(2)}$ & $\mathbf{9 4}^{(2)}$ & & & & & \\
\hline Dicliptera scutellata Griseb. & $50^{(2)}$ & $83^{(1)}$ & & $14^{(+)}$ & & & \\
\hline Nassella cordobensis (Speg.) Barkworth* & $20^{(1)}$ & $83^{(1)}$ & $45^{(+)}$ & $14^{(1)}$ & & & \\
\hline Iresine diffusa Humb. \& Bonpl. ex Willd. var. diffusa & $50^{(+)}$ & $78^{(1)}$ & & $71^{(1)}$ & & & \\
\hline Anredera cordifolia (Ten.) Steenis & $10^{(+)}$ & $61^{(+)}$ & $3^{(+)}$ & $57^{(+)}$ & & & \\
\hline Colletia spinosissima J.F. Gmel. & $10^{(+)}$ & $61^{(2)}$ & $3^{(2)}$ & & & & \\
\hline Metastelma tubatum Griseb.* & $20^{(1)}$ & $61^{(1)}$ & & $71^{(1)}$ & & & \\
\hline Plumbago caerulea Kunth & $40^{(1)}$ & $56^{(1)}$ & & $14^{(+)}$ & & & \\
\hline Stevia satureiifolia (Lam.) Sch. Bip. ex Klotzsch var. satureiifolia* & $10^{(+)}$ & $56^{(1)}$ & $3^{(+)}$ & & & & \\
\hline Deuterocohnia longipetala (Baker) Mez & & $50^{(1)}$ & & & & & \\
\hline Minthostachys verticillata (Griseb.) Epling* & $30^{(1)}$ & $5 \mathbf{0}^{(1)}$ & & & & & \\
\hline Baccharis flabellata Hook. \& Arn. ${ }^{\circ}$ & & $28^{(+)}$ & & & & & \\
\hline \multicolumn{8}{|l|}{ Especies típicamente encontradas en 2.1} \\
\hline Aristida mendocina Phil. & & & $97^{(2)}$ & $14^{(3)}$ & & & \\
\hline Parthenium hysterophorus L. & & $6^{(+)}$ & $76^{(2)}$ & & & & \\
\hline Bothriochloa barbinodis (Lag.) Herter & & $22^{(+)}$ & $72^{(1)}$ & $43^{(1)}$ & & & \\
\hline Schkuhria pinnata (Lam.) Kuntze ex Thell. & & & $59^{(1)}$ & $29^{(1)}$ & & & \\
\hline Cyperus aggregatus (Willd.) Endl. var. aggregatus & & $6^{(+)}$ & $55^{(+)}$ & & & & \\
\hline Lantana megapotamica (Spreng.) Tronc. & $20^{(1)}$ & & $\mathbf{5 2}^{(1)}$ & $29^{(+)}$ & & & \\
\hline Heliotropium campestre Griseb. & $20^{(+)}$ & & $48^{(+)}$ & & & & \\
\hline Tragus australianus Blake† & & & $41^{(1)}$ & & & & \\
\hline Heterosperma ovatifolium Cav. & & $33^{(+)}$ & $38^{(+)}$ & $100^{(+)}$ & & & \\
\hline Setaria leucopila (Scribn. \& Merr.) K. Schum. & & $39^{(1)}$ & $34^{(1)}$ & $100^{(1)}$ & & & \\
\hline Tagetes minuta L. & $30^{(+)}$ & $67^{(2)}$ & $31^{(1)}$ & $100^{(1)}$ & & & \\
\hline Schinus fasciculatus (Griseb.) I.M. Johnst. var. fasciculatus & $60^{(+)}$ & $56^{(1)}$ & $10^{(+)}$ & $\mathbf{8 6}^{(1)}$ & & $8^{+}$ & \\
\hline Amphilophium carolinae (Lindl.) L. G. Lohmann & $30^{(+)}$ & $33^{(+)}$ & $17^{(1)}$ & $71^{(1)}$ & & & \\
\hline Cologania broussonetii (Balb.) DC. & & & & $71^{(+)}$ & & & \\
\hline Sida dictyocarpa Griseb. ex K. Schum. & $10^{(1)}$ & & & $71^{(+)}$ & & & \\
\hline $\begin{array}{l}\text { Austrobrickellia patens (D. Don ex Hook. \& Arn.) R.M. King \& H. } \\
\text { Rob. }\end{array}$ & & & & $\mathbf{5 7} \mathbf{7}^{(1)}$ & & & \\
\hline Cantinoa mutabilis (Rich.) Harley \& J.F.B. Pastore & $10^{(+)}$ & $11^{(+)}$ & $14^{(+)}$ & $57^{(1)}$ & & & \\
\hline Gouinia latifolia (Griseb.) Vasey & $10^{(+)}$ & & $14^{(+)}$ & $5 \mathbf{7}^{(+)}$ & & & \\
\hline Melochia argentina R.E. Fr. & & $11^{(+)}$ & & $43^{(+)}$ & & & \\
\hline Araujia brachystephana (Griseb.) Fontella \& Goyder & & & & $29^{(+)}$ & & & \\
\hline Ipomoea nil (L.) Roth & & & & $29^{(+)}$ & & & \\
\hline \multicolumn{8}{|l|}{ Especies típicamente encontradas en 3.1} \\
\hline Digitaria sanguinalis (L.) Scop. $\dagger$ & & & & & $94^{(2)}$ & $8^{(+)}$ & $83^{(1)}$ \\
\hline Sorghum halepense (L.) Pers. var. halepense† & & & & & $\mathbf{8 8}^{(1)}$ & $17^{(+)}$ & \\
\hline Cyperus rotundus L. $\dagger$ & & & & & $31^{(+)}$ & & \\
\hline \multicolumn{8}{|l|}{ Especies típicamente encontradas en 3.2} \\
\hline Chloris virgata Sw. & & & & & $6^{(+)}$ & $75^{(1)}$ & $17^{(+)}$ \\
\hline Eleusine indica (L.) Gaertn.† & & & & & $62^{(1)}$ & $75^{(2)}$ & \\
\hline Anoda cristata (L.) Schltdl. & & & & & $31^{(+)}$ & $50^{(+)}$ & \\
\hline
\end{tabular}


J. J. Cantero et al. - Heterogeneidad de la vegetación en ambientes basálticos

\begin{tabular}{|c|c|c|c|c|c|c|c|}
\hline \multirow{2}{*}{$\begin{array}{l}\text { Geoforma } \\
\text { Grupos y subgrupos }\end{array}$} & \multicolumn{2}{|c|}{$\mathrm{I}$} & \multicolumn{2}{|c|}{$\mathrm{MN}$} & \multicolumn{3}{|c|}{ MA } \\
\hline & 1.1 & 1.2 & 2.1 & 2.2 & 3.1 & 3.2 & 3.3 \\
\hline & 10 & 18 & 29 & 7 & 16 & 12 & 6 \\
\hline Conyza bonariensis (L.) Cronquist var. bonariensis & & $6^{(+)}$ & & & $6^{(+)}$ & $5 \mathbf{0}^{(1)}$ & $33^{(+)}$ \\
\hline Cynodon dactylon (L.) Pers. var. dactylon† & & & & & & $25^{(+)}$ & \\
\hline Borreria spinosa (L.) Cham. \& Schltdl. & & & $3^{(+)}$ & & $6^{(+)}$ & & $100^{(2)}$ \\
\hline Cyperus haspan L. var. haspan & & & & & & & $50^{(+)}$ \\
\hline Mitracarpus megapotamicus (Spreng.) Kuntze & & & & & & & $33^{(+)}$ \\
\hline \multicolumn{8}{|l|}{ Especies preferentes de I y MN } \\
\hline Acacia caven (Molina) Molina var. caven & $100^{(3)}$ & $72^{(1)}$ & $97^{(2)}$ & $71^{(2)}$ & & $8^{(+)}$ & $67^{(+)}$ \\
\hline Salvia cuspidata Ruiz \& Pav. ssp. gilliesii (Benth.) J.R.I. Wood & $100^{(2)}$ & $89^{(+)}$ & $86^{(1)}$ & $86^{(1)}$ & & & \\
\hline Zinnia peruviana (L.) L. & $100^{(2)}$ & $83^{(1)}$ & $86^{(1)}$ & $71^{(+)}$ & & & \\
\hline $\begin{array}{l}\text { Aloysia gratissima (Gillies \& Hook. ex Hook.) Tronc. var. } \\
\text { gratissima }\end{array}$ & $100^{(1)}$ & $83^{(1)}$ & $62^{(2)}$ & $100^{(1)}$ & & & \\
\hline Bidens subalternans DC. var. subalternans & $100^{(1)}$ & $72^{(1)}$ & $55^{(1)}$ & $100^{(1)}$ & $6^{(+)}$ & & \\
\hline Commelina erecta L. var. angustifolia (Michx.) Fernald & $100^{(1)}$ & $72^{(1)}$ & $62^{(+)}$ & $57^{(+)}$ & $6^{(+)}$ & $8^{(+)}$ & \\
\hline Celtis ehrenbergiana (Klotzsch) Liebm. var. ehrenbergiana & $90^{(1)}$ & $83^{(2)}$ & $41^{(1)}$ & $100^{(1)}$ & & & \\
\hline Gomphrena perennis L. var. perennis & $90^{(1)}$ & $61^{(+)}$ & $55^{(+)}$ & $57^{(+)}$ & & & \\
\hline Lantana fucata Lindl. & $80^{(1)}$ & $83^{(1)}$ & $17^{(1)}$ & $71^{(1)}$ & & & \\
\hline Condalia microphylla Cav.* & $70^{(+)}$ & $78^{(1)}$ & $21^{(+)}$ & $71^{(+)}$ & & & \\
\hline Abutilon pauciflorum A. St.-Hil. & $30^{(1)}$ & $33^{(+)}$ & $41^{(+)}$ & $57^{(1)}$ & & & \\
\hline Opuntia sulphurea Gillies ex Salm-Dyck var. sulphurea & $60^{(+)}$ & $28^{(+)}$ & $24^{(+)}$ & & & & \\
\hline Cardiospermum halicacabum L. var. halicacabum & $60^{(+)}$ & $17^{(+)}$ & $28^{(+)}$ & & & & \\
\hline Gaya parviflora (Phil.) Krapov. & $60^{(1)}$ & $22^{(+)}$ & $52^{(+)}$ & & & & \\
\hline Boerhavia diffusa L. var. diffusa & $50^{(1)}$ & $11^{(+)}$ & $31^{(1)}$ & & & & \\
\hline Janusia guaranitica (A. St.-Hil.) A. Juss. & $40^{(+)}$ & $39^{(+)}$ & $31^{(+)}$ & $57^{(+)}$ & & & \\
\hline Sida argentina K. Schum. var. argentina & $10^{(+)}$ & & $48^{(1)}$ & $43^{(+)}$ & & & \\
\hline Acalypha communis Müll. Arg. & $20^{(+)}$ & $11^{(+)}$ & $31^{(+)}$ & $29^{(1)}$ & & & \\
\hline Dichondra microcalyx (Hallier f.) Fabris & $20^{(+)}$ & $33^{(+)}$ & $14^{(+)}$ & $43^{(+)}$ & & & \\
\hline Galactia glaucophylla Harms ${ }^{\circ}$ & $30^{(1)}$ & $39^{(+)}$ & $17^{(+)}$ & & & & \\
\hline Mitracarpus megapotamicus (Spreng.) Kuntze & & & & & & & $33^{(+)}$ \\
\hline Salpichroa origanifolia (Lam.) Baill. & $30^{(+)}$ & $28^{(+)}$ & $14^{(+)}$ & $14^{(+)}$ & & & \\
\hline Sida spinosa L. & $50^{(+)}$ & $17^{(+)}$ & $14^{(+)}$ & $14^{(+)}$ & & & \\
\hline Chromolaena arnottiana (Griseb.) R.M. King \& H. Rob. & $10^{(+)}$ & $28^{(1)}$ & $10^{(+)}$ & $43^{(1)}$ & & & \\
\hline Glandularia tenera (Spreng.) Cabrera & $20^{(+)}$ & & $34^{(+)}$ & & & & \\
\hline Tillandsia capillaris Ruiz \& Pav. & $20^{(+)}$ & $28^{(+)}$ & $14^{(+)}$ & $14^{(+)}$ & & & \\
\hline Cestrum parqui L'Hér.* & $40^{(+)}$ & $6^{(+)}$ & $14^{(+)}$ & $29^{(+)}$ & & & \\
\hline Solanum stuckertii Bitter & $30^{(+)}$ & $39^{(+)}$ & $3^{(+)}$ & & & & \\
\hline Chaptalia integerrima (Vell.) Burkart & $30^{(+)}$ & $28^{(+)}$ & $3^{(+)}$ & $14^{(+)}$ & & & \\
\hline Echinopsis aurea Britton \& Rose var. Aurea ${ }^{\circ}$ & $30^{(+)}$ & & $24^{(+)}$ & & & & \\
\hline Opuntia salmiana Parm. & $40^{(+)}$ & $22^{(+)}$ & $3^{(+)}$ & $14^{(+)}$ & & & \\
\hline Sida rhombifolia L. & $10^{(+)}$ & $17^{(+)}$ & $14^{(+)}$ & $29^{(+)}$ & & & \\
\hline Argyrochosma nivea (Poir.) Windham var. nivea & $40^{(+)}$ & $28^{(+)}$ & & & & & \\
\hline Pseudabutilon virgatum (Cav.) Fryxell & $40^{(1)}$ & $28^{(+)}$ & & & & & \\
\hline Cheilanthes micropteris Sw. & $40^{(+)}$ & $22^{(+)}$ & & & & & \\
\hline Cleome aculeata L. var. cordobensis (Eichler \& Griseb.) Kuntze & $40^{(+)}$ & & $7^{(+)}$ & $29^{(+)}$ & & & \\
\hline Setaria cordobensis R.A.W. Herrm. * & $30^{(+)}$ & $17^{(+)}$ & $7^{(1)}$ & & & & \\
\hline Exhalimolobos weddellii (E. Fourn.) Al-Shehbaz \& C.D. Bailey & $40^{(+)}$ & $17^{(+)}$ & & & & & \\
\hline Microliabum candidum (Griseb.) H. Rob.* & $40^{(+)}$ & $17^{(+)}$ & & & & & \\
\hline Portulaca obtusa Poelln.* & $40^{(1)}$ & & $7^{(+)}$ & $14^{(+)}$ & & & \\
\hline Rhynchosida physocalyx (A. Gray) Fryxell & $30^{(+)}$ & $6^{(+)}$ & $10^{(+)}$ & & & & \\
\hline Cheilanthes buchtienii (Rosenst.) R.M. Tryon & $30^{(1)}$ & $6^{(+)}$ & $7^{(+)}$ & & & & \\
\hline
\end{tabular}


Bol. Soc. Argent. Bot. 52 (1) 2017

\begin{tabular}{|c|c|c|c|c|c|c|c|}
\hline \multirow{2}{*}{$\begin{array}{l}\text { Geoforma } \\
\text { Grupos y subgrupos }\end{array}$} & \multicolumn{2}{|c|}{1} & \multicolumn{2}{|c|}{ MN } & \multicolumn{3}{|c|}{ MA } \\
\hline & 1.1 & 1.2 & 2.1 & 2.2 & 3.1 & 3.2 & 3.3 \\
\hline$N^{\circ}$ Censos & 10 & 18 & 29 & 7 & 16 & 12 & 6 \\
\hline Cheilanthes myriophylla Desv. & $30^{(+)}$ & $17^{(+)}$ & & & & & \\
\hline Solanum sarrachoides Sendtn. & $30^{(+)}$ & $11^{(+)}$ & & $14^{(+)}$ & & & \\
\hline Lepechinia floribunda (Benth.) Epling & $30^{(+)}$ & $6^{(+)}$ & $3^{(+)}$ & & & & \\
\hline Schizachyrium spicatum (Spreng.) Herter & $30^{(1)}$ & & $7^{(+)}$ & & & & \\
\hline Anemia tomentosa (Savigny) Sw. var. tomentosa & $30^{(+)}$ & & $3^{(+)}$ & & & & \\
\hline Bidens pilosa L. var. pilosa & & $39^{(1)}$ & $21^{(2)}$ & $29^{(+)}$ & & & \\
\hline Clematis montevidensis Spreng. var. montevidensis & & $33^{(+)}$ & $17^{(1)}$ & $29^{(+)}$ & & $8^{(+)}$ & \\
\hline Paspalum malacophyllum Trin. & & $28^{(+)}$ & $7^{(+)}$ & $43^{(1)}$ & & & \\
\hline Setaria parviflora (Poir.) Kerguélen var. parviflora & & $11^{(+)}$ & $17^{(+)}$ & $43^{(1)}$ & & & \\
\hline Rivina humilis L. & & $33^{(+)}$ & & $29^{(+)}$ & & & \\
\hline Melinis repens (Willd.) Zizka† & & $6^{(+)}$ & $31^{(2)}$ & & & & \\
\hline Selaginella sellowii Hieron. & & $6^{(2)}$ & $38^{(1)}$ & $29^{(+)}$ & & & \\
\hline Paspalum humboldtianum Flüggé & & $22^{(1)}$ & $10^{(+)}$ & & & & \\
\hline Mandevilla pentlandiana (A. DC.) Woodson & & $28^{(1)}$ & & $29^{(+)}$ & & & \\
\hline Paspalum notatum var. notatum & & & $31^{(1)}$ & $14^{(+)}$ & & & \\
\hline \multicolumn{8}{|l|}{ Especies preferentes de MA } \\
\hline Ipomoea purpurea (L.) Roth & & & & $43^{(+)}$ & $56^{(+)}$ & $67^{(1)}$ & \\
\hline Pombalia parviflora (Mutis ex L.f.) Paula-Souza & & & & & $31^{(+)}$ & $17^{(+)}$ & $33^{(+)}$ \\
\hline \multicolumn{8}{|l|}{ Especies ubicuas } \\
\hline Cheilanthes buchtienii (Rosenst.) R.M. Tryon & $30^{(1)}$ & $6^{(+)}$ & $7^{(+)}$ & & & & \\
\hline Chenopodium album L. $†$ & $10^{(+)}$ & $17^{(+)}$ & & $29^{(+)}$ & & $8^{(+)}$ & $33^{(1)}$ \\
\hline Dichondra sericea Sw. var. sericea & $30^{(1)}$ & $6^{(+)}$ & $7^{(+)}$ & & $6^{(+)}$ & & $17^{(+)}$ \\
\hline $\begin{array}{l}\text { Galium richardianum (Gillies ex Hook. \& Arn.) Endl. ex Walp. ssp. } \\
\text { richardianum }\end{array}$ & $30^{(+)}$ & $17^{(+)}$ & $3^{(+)}$ & & & & $17^{(+)}$ \\
\hline \multicolumn{8}{|l|}{ Especies acompañantes } \\
\hline Vernonanthura nudiflora (Less.) H. Rob. f. nudiflora & & & $10^{(+)}$ & & & & \\
\hline Acmella decumbens (Sm.) R.K. Jansen var. decumbens & & $11^{(+)}$ & & & & & \\
\hline Apodanthera sagittifolia (Griseb.) Mart.Crov. var. sagittifolia & $20^{(+)}$ & $11^{(+)}$ & & & & & \\
\hline Eryngium horridum Malme & $20^{(+)}$ & & & & $6^{(+)}$ & & $17^{(2)}$ \\
\hline Rhynchosia senna Gillies ex Hook. var. senna & $20^{(+)}$ & $11^{(+)}$ & & & & & \\
\hline Silene argentina (Pax) Bocquet ${ }^{*}$ & $20^{(+)}$ & $6^{(+)}$ & & & & & \\
\hline Euphorbia hyssopifolia L. & $20^{(+)}$ & $6^{(+)}$ & & & & & \\
\hline Galactia latisiliqua Desv. & $20^{(+)}$ & & & & & & \\
\hline Sacoila lanceolata (Aubl.) Garay & $20^{(+)}$ & $6^{(+)}$ & & & & & \\
\hline Solanum hieronymi Kuntze & $20^{(+)}$ & & $3^{(+)}$ & & & & \\
\hline Lippia turbinata Griseb. f. turbinata & $10^{(+)}$ & $17^{(+)}$ & $10^{(+)}$ & $14^{(1)}$ & & & \\
\hline Woodsia montevidensis (Spreng.) Hieron. & $10^{(+)}$ & $11^{(+)}$ & $3^{(+)}$ & & & & \\
\hline Cereus aethiops Haw. & $10^{(+)}$ & $6^{(+)}$ & $3^{(+)}$ & & & & \\
\hline Dolichandra cynanchoides Cham. & $10^{(+)}$ & $11^{(+)}$ & & & & & \\
\hline Pombalia serrata (Phil.) Paula-Souza* & $10^{(+)}$ & $6^{(+)}$ & $3^{(+)}$ & & & & \\
\hline Baccharis coridifolia DC. & $10^{(+)}$ & & $3^{+1}$ & & & & \\
\hline Capsicum chacoense Hunz. & $10^{(+)}$ & $6^{(+)}$ & & & & & \\
\hline Euphorbia serpens Kunth var. serpens & $10^{(+)}$ & & & & $6^{(+)}$ & & \\
\hline Geoffroea decorticans (Gillies ex Hook. \& Arn.) Burkart & $10^{(+)}$ & & $3^{(+)}$ & & & & \\
\hline Gymnocalycium bruchii (Speg.) Hosseus var. bruchii• & $10^{(+)}$ & & $3^{(+)}$ & & & & \\
\hline Lycium chilense Miers ex Bertero var. chilense & $10^{(+)}$ & & $3^{(+)}$ & & & & \\
\hline Piptochaetium montevidense (Spreng.) Parodi & $10^{(1)}$ & & & $14^{(+)}$ & & & \\
\hline Mitracarpus megapotamicus (Spreng.) Kuntze & $10^{(+)}$ & $11^{(+)}$ & $17^{(+)}$ & & & & \\
\hline
\end{tabular}


J. J. Cantero et al. - Heterogeneidad de la vegetación en ambientes basálticos

\begin{tabular}{|c|c|c|c|c|c|c|c|}
\hline Geoforma & - & & & & & MA & \\
\hline Grupos y subgrupos & 1.1 & 1.2 & 2.1 & 2.2 & 3.1 & 3.2 & 3.3 \\
\hline $\mathrm{N}^{\circ}$ Censos & 10 & 18 & 29 & 7 & 16 & 12 & 6 \\
\hline $\begin{array}{l}\text { Harrisia pomanensis (F.A.C. Weber ex K. Schum.) Britton \& Rose } \\
\text { ssp. pomanensis }\end{array}$ & $10^{(+)}$ & $17^{(+)}$ & & & & & \\
\hline Baccharis ulicina Hook. \& Arn. & $10^{+}$ & $6^{+}$ & 101 & & & & \\
\hline Parietaria debilis G. Forst. & $10^{(+)}$ & $6^{(+)}$ & & & & $17^{(+)}$ & \\
\hline Passiflora foetida L. var. foetida & $10^{(+)}$ & $6^{(+)}$ & $7^{(+)}$ & & & & \\
\hline Jarava ichu Ruiz \& Pav. var. ichu & & $22^{(+)}$ & $7^{(+)}$ & $14^{(+)}$ & & & \\
\hline Euphorbia dentata Michx. & & $17^{(+)}$ & $3^{(+)}$ & $14^{(+)}$ & & & \\
\hline Mentzelia albescens (Gillies ex Arn.) Griseb. & & $17^{(1)}$ & $14^{(1)}$ & & & & \\
\hline Malvastrum coromandelianum (L.) Garcke ssp. coromandelianum & & $11^{(+)}$ & $7^{(+)}$ & $14^{(+)}$ & & & \\
\hline Simsia dombeyana DC. & & $17^{(+)}$ & $10^{(+)}$ & $14^{(+)}$ & & & \\
\hline Angelphytum aspilioides (Griseb.) H. Rob.. & & $17^{(+)}$ & $10^{(1)}$ & & & & \\
\hline Setaria lachnea (Nees) Kunth & & $17^{(+)}$ & $3^{(+)}$ & & & & \\
\hline Wissadula gymnanthemum (Griseb.) K. Schum. & & $17^{(+)}$ & & $14^{(+)}$ & & & \\
\hline Ximenia americana L. var. americana & & $11^{(+)}$ & $10^{(+)}$ & & & & \\
\hline Herissantia crispa (L.) Brizicky & & $11^{(+)}$ & $17^{(+)}$ & & & & \\
\hline Pappophorum phillippianum Parodi* & & $6^{(+)}$ & $7^{(1)}$ & & & & \\
\hline Asplenium monanthes $\mathrm{L}$. & & $6^{(+)}$ & $3^{(+)}$ & & & & \\
\hline Baccharis glutinosa Pers. & & $6^{(+)}$ & $3^{(+)}$ & & & & \\
\hline Heteropogon contortus (L.) P. Beauv. ex Roem. \& Schult. & & $6^{(+)}$ & $3^{(+)}$ & & & & \\
\hline Sonchus oleraceus L. $\dagger$ & & $6^{(+)}$ & & & & $8^{(+)}$ & \\
\hline Lantana balansae Briq. & & $6^{(1)}$ & $14^{(1)}$ & & & & \\
\hline Borreria eryngioides Cham. \& Schltdl. var. eryngioides ${ }^{*}$ & & & $14^{(1)}$ & & & $8^{(+)}$ & \\
\hline Chloris ciliata Sw. f. ciliata & & & $10^{(+)}$ & & $6^{(1)}$ & & \\
\hline Portulaca oleraceae L. $\dagger$ & & & $3^{(+)}$ & & $6^{(+)}$ & $17^{(+)}$ & $17^{(+)}$ \\
\hline Euphorbia hirta L. var. hirta† & & & $3^{(+)}$ & & $12^{(+)}$ & & \\
\hline Datura ferox L. $\dagger$ & & & & & $12^{(+)}$ & $8^{(+)}$ & \\
\hline Cyperus esculentus L. var. esculentus $\dagger$ & & & & & $19^{+}$ & & $17^{+}$ \\
\hline Ipomoea rubriflora O'Donell & & & & & $19^{+}$ & $8^{+}$ & \\
\hline Amaranthus standleyanus Parodi ex Covas & & & & $14^{+}$ & & & 171 \\
\hline Bouchetia anomala (Miers) Britton \& Rusby & $20^{(+)}$ & & & & & & \\
\hline Gymnocalycium calochlorum (Boed.) Y. Ito• & $20^{(+)}$ & & & & & & \\
\hline Carex trachycystis Griseb. & $20^{(+)}$ & & & & & & \\
\hline Ligaria cuneifolia (Ruiz \& Pav.) Tiegh. & $20^{(+)}$ & & & & & & \\
\hline Nassella filiculmis (Delile) Barkworth & $20^{(+)}$ & & & & & & \\
\hline Nassella neesiana (Trin. \& Rupr.) Barkworth & $20^{(1)}$ & & & & & & \\
\hline Amaranthus hybridus L. ssp. hybridus $\dagger$ & $20^{(+)}$ & & & & & & \\
\hline Baccharis sessiliflora Vahl & $20^{(+)}$ & & & & & & \\
\hline Mandevilla laxa (Ruiz \& Pav.) Woodson & & $22^{(+)}$ & & & & & \\
\hline Pleopeltis pinnatifida Gillies ex Hook. \& Grev. & & $11^{(+)}$ & & & & & \\
\hline Polygala stenophylla A. Gray* & & $11^{(+)}$ & & & & & \\
\hline Lithraea molleoides (Vell.) Engl. & & $17^{(+)}$ & & & & & \\
\hline Eustachys distichophylla (Lag.) Nees & & $11^{(+)}$ & & & & & \\
\hline Tragia volubilis $\mathrm{L}$. & & $11^{(+)}$ & & & & & \\
\hline Eustachys retusa (Lag.) Kunth & & & $21^{(1)}$ & & & & \\
\hline Nierembergia linariaefolia Graham var. linariaefolia & & & $14^{(+)}$ & & & & \\
\hline Acalypha poiretii Spreng. & & & $10^{(+)}$ & & & & \\
\hline Heterosperma tenuisectum (Griseb.) Cabrera & & & $7^{(+)}$ & & & & \\
\hline Mollugo verticillata L. $\dagger$ & & & $7^{(+)}$ & & & & \\
\hline
\end{tabular}




\begin{tabular}{|c|c|c|c|c|c|c|c|}
\hline Geoforma & \multicolumn{2}{|c|}{ I } & \multicolumn{2}{|c|}{$\mathrm{MN}$} & \multicolumn{3}{|c|}{ MA } \\
\hline Grupos y subgrupos & 1.1 & 1.2 & 2.1 & 2.2 & 3.1 & 3.2 & 3.3 \\
\hline$N^{\circ}$ Censos & 10 & 18 & 29 & 7 & 16 & 12 & 6 \\
\hline Cenchrus myosuroides Kunth & & & $7^{(+)}$ & & & & \\
\hline Croton hirtus L'Hér. & & & $7^{(+)}$ & & & & \\
\hline Tillandsia pedicellata (Mez) A. Cast. & & & $7^{(+)}$ & & & & \\
\hline Glandularia platensis (Spreng.) Schnack \& Covas & & & $7^{(+)}$ & & & & \\
\hline Echinochloa colona (L.) Link† & & & & $19^{(2)}$ & & & \\
\hline Xanthium strumarium L. & & & & $12^{(1)}$ & & & \\
\hline Ulmus pumila L. $\dagger$ & & & & & $17^{(+)}$ & & \\
\hline
\end{tabular}

† Especies exóticas; *, Especies endémicas nacionales; ’ , Especies endémicas regionales; • Especies endémicas locales.

y Schkuhria pinnata. La presencia de isletas de forma irregular dominadas por Schinus fasciculatus var. fasciculatus diferencia al sub-grupo 2.2 y es allí donde se registran las especies de enredaderas Amphilophium carolinae, Austrobrickellia patens, Araujia brachystephana e Ipomoea nil, con alto valor diagnóstico de este subgrupo.

Grupo 3. Digitaria sanguinalis - Eleusine indica Borreria spinosa

Este grupo de inventarios corresponde a las planicies suavemente onduladas con reemplazo total de la vegetación natural (i.e., Matriz Agrícola) y se compone de un conjunto de especies consideradas típicamente como malezas en los agroecositemas del centro de Argentina (por ej., Anoda cristata, Cynodon dactylon, Cyperus esculentus, Cyperus rotundus, Datura ferox, Digitaria sanguinalis, Echinochloa colonum, Eleusine indica, Galinsoga parviflora, Sonchus asper y Sorghum halepense). Fisonómicamente, se trata de herbazales abiertos dominados alternativamente por Sorghum halepense, Chloris virgata y Cyperus aggregatus var. aggregatus, junto a las especies que dan el nombre al grupo. Pueden reconocerse tres sub-grupos dentro de esta unidad (Tabla 1, Fig. 2). El sub-grupo 3.1 comprende a las especies diagnósticas asociadas a las situaciones de máxima perturbación por laboreo entre las que se destaca, además de las especies ya citadas, Cyperus rotundus, una geófita nativa. El segundo sub-grupo (3.2 en la Tabla 1) incluye inventarios con terófitas nativas que se comportan típicamente como malezas de cultivos, tal es el caso de Chloris virgata y Conyza bonariensis. Finalmente, el sub-grupo 3.3 incluye los relevamientos localizados en los sitios de la
Matriz Agrícola menos perturbados, como los bordes periféricos a la matriz natural (MN) donde se destaca, además de las especies dominantes ya citadas, la terófita nativa Mitracarpus megapotamicus.

\section{Riqueza y diversidad de especies}

Los valores más altos de riqueza fueron hallados en las I ( $S=209)$ y MN ( $S=163)$. En cambio, en la MA las profundas perturbaciones se reflejaron en una caída abrupta del número de especies registrado $(\mathrm{S}=56)$. A excepción de la equitatividad $(0.96,0.95$ y 0.95 para I, MN y MA, respectivamente), tanto la riqueza promedio de especies por censo (49.18, 29.03 y 6.00 en I, MN y MA, respectivamente), como la diversidad (3.71, 3.18 y 1.68 , respectivamente) y la dominancia $(0.97,0.95$ y 0.79 para I, MN y MA, respectivamente), mostraron diferencias significativas entre los tres tipos de hábitats $(\mathrm{F}=$ $2.49, \mathrm{p}<0.0887 ; \mathrm{F}=261.06, \mathrm{p}<0.0001 ; \mathrm{F}=667.55$, $\mathrm{p}<0.0001 ; \mathrm{F}=408.82, \mathrm{p}<0.0001$, respectivamente).

\section{Espectros de formas de vida}

Los espectros de formas de vida exhiben similitudes importantes entre I y MN y se diferenciaron notablemente de MA, donde hubo una simplificación en la estructura observada en la comunidad. Todas las formas de vida (16) estuvieron presentes en las I. Las Hierbas Perennes, Arbustos y Enredaderas fueron más importantes en I y MN, mientras que las Hierbas Anuales y las Hierbas Perennes Siempreverdes lo fueron en MA (Fig. 5). En MN no se registraron Parásitas ni Bromeliáceas mientras que en MA, además de esas formas de vida, tampoco se registraron Arbustos, Cactáceas, Epífitos y Helechos (Fig. 5, Apéndice). 


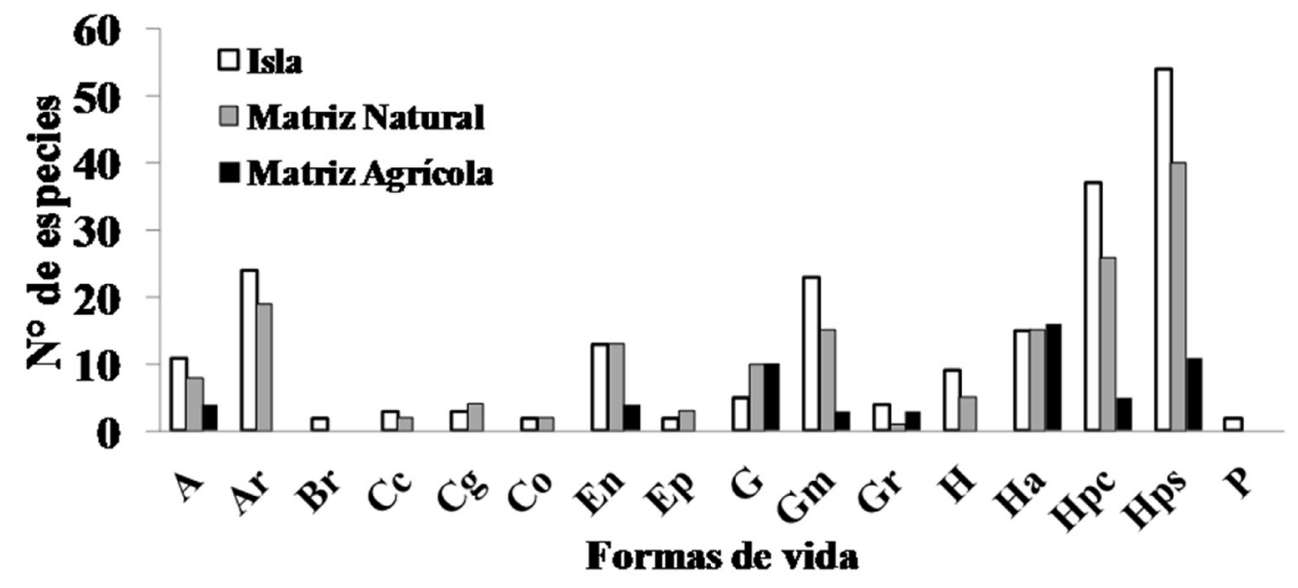

Fig. 5. Espectros de formas de vida de las especies de plantas vasculares de los afloramientos basálticos (I, color blanco) y matrices circundantes (MN, color gris; MA, negro) de la Sierra de Los Cóndores (Córdoba, Argentina). Abreviaturas: Árboles, A; Arbustos, Ar; Arbustos Parásitos, Ap; Bromeliáceas, Br; Cactáceas Columnares, Cc; Cactáceas Globulares, Cg; Cactáceas Opuntioides, Co; Enredaderas, En; Epífitas, Ep; Gramíneas, G; Graminoides, Gr; Gramíneas en Mata, Gm; Hierbas Anuales, Ha; Helechos, H; Hierbas Perennes Caducifolias, Hpc; Hierbas Perennes Siempre verdes, Hps; Parásitas, P.

\section{Flora endémica}

La endemoflora de los afloramientos basálticos y sus ambientes asociados comprende 39 spp. y se compone de $4 \mathrm{spp}$. endémicas locales, 5 endémicas regionales y 30 endémicas nacionales (Apéndice). Cinco familias reúnen el $58.97 \%$ de las especies endémicas: Asteraceae (25.64\%), Poaceae (15.38\%), Cactaceae (12.82\%), Fabaceae (2.56\%), y Malvaceae (2.56\%). El género de Cactaceae Gymnocalycium incluye tanto especies endémicas regionales (por ej., Gymnocalycium bruchii var. bruchii y Gymnocalycium ochoterenae ssp. ochoterenae) como endémicas locales (por ej., Gymnocalycium calochalorum y Gymnocalycium erinaceum). El número de especies endémicas fue mayor en las Islas (35), intermedio en la Matriz Natural (19) y menor en la Matriz Agrícola (3). Se registró el mismo número (2) de endémicas locales en I y MN, las cuales no estuvieron presentes en MA. Las especies endémicas regionales estuvieron representadas en los tres hábitats $(5,2$ y 2 en I, MN y MA, respectivamente), mientras las endémicas nacionales fueron numerosas en I (28) y en MN (15), estando representadas sólo con un taxón en MA. En I se destacan como endémicas regionales
Baccharis flabellata, en MN, Echinopsis aurea var. aurea y Galactia glaucophylla y en MA, Sphaeralcea cordobensis.

Importancia relativa de los corotipos y de las especies nativas y exóticas

Los corotipos mejor representados en el elenco florístico completo de los afloramientos basálticos son el Chaqueño occidental (43.15\%) y el Austrobrasilero $(40.32 \%)$, seguidos por el corotipo Orófilo bajo $(12.10 \%)$ y el Andino (11\%) (Apéndice). Se registraron 24 spp. exóticas en los hábitats estudiados; la mayor parte de ellas se presentó en MA (20 spp.), mientras que en I hubo sólo cuatro y en MN seis especies exóticas. Chenopodium album fue la única especie exótica presente en los tres tipos de hábitats, mientras que Melinis repens, Mollugo verticillata y Tragus australianus se registraron sólo en I y MN. No hubo árboles exóticos en I y MN pero si en MA (Ulmus pumila y Gleditsia triacanthos).

Los cambios en la relación nativas/exóticas reflejan el gradiente de perturbación creciente desde las islas rocosas hasta la matriz agrícola circundante: I (205 spp. nativas, 4 spp. exóticas), 
MN (158 spp. nativas, 5 exóticas) y MA (36 spp. nativas, 19 exóticas) (Tabla 1$)$.

\section{Discusión}

Nuestros resultados ponen de manifiesto la importancia de los afloramientos basálticos de la Sierra de Los Cóndores, en el centro de la República Argentina. Las comunidades vegetales observadas en estos afloramientos no son uniformes, sino más bien exhiben diferencias importantes en su composición florística y en los ambientes que ocupan. A partir de los hallazgos reportados, se reconoce el valor de las mesadas y conos desde el punto de vista de la conservación de la diversidad florística y se establece un gradiente de degradación que culmina con la matriz circundante como un sistema completamente modificado por las actividades humanas. En consecuencia, a los efectos de representar adecuadamente las variaciones en composición a lo largo de las diferentes geoformas, se propone que las futuras áreas protegidas deberían abarcar no sólo el gradiente regional de variación de los ambientes basálticos de Córdoba y del centro del país (Ver en Cantero et al., 2016), sino también el gradiente local de variación entre y dentro de los afloramientos observado en este estudio.

Las familias mejor representadas en los ambientes basálticos estudiados, fueron Asteraceae, Poaceae y Fabaceae, que son también las más numerosas en el Distrito Chaqueño Serrano, al cual pertenece este territorio (Cabrera, 1976; Zuloaga et al., 2008; Giorgis et al., 2011). En comparación a otras comunidades de ambientes rocosos del centro de Argentina (Funes \& Cabido, 1995; Cantero et al., 2011), las Islas rocosas y la Matriz Natural poseen una flora rica y variada donde dominan las Eudicotiledóneas. El clado de las Monocotiledóneas está principalmente representado por Poaceae, con algunas especies codominantes de la composición florística. A su vez, las especies terrestres de Bromeliaceae se destacan en el ambiente típicamente rupícola de las Islas rocosas, donde Dyckia floribunda y Deuterocohnia longipetala llegan a ser dominantes en algunos inventarios. Un patrón similar fue reportado por Cantero et al. (2016) para otros afloramientos basálticos ubicados en distintas provincias del centro del país.
Un resultado relevante de este estudio es que la composición florística difirió entre las Islas rocosas, la Matriz Natural y la Matriz Agrícola. Casi el $50 \%$ de las especies registradas fue exclusivo de alguno de los tres hábitats y tan sólo 12 taxones fueron compartidos por todas las geoformas. Este resultado parece ser característico en la vegetación de afloramientos rocosos en general y ha sido reportado por diversos autores, incluso en casos en que la heterogeneidad ambiental parece ser menos evidente que en nuestro sitio de estudio (Norris \& Thomas, 1991; Cabido et al., 1990; Funes \& Cabido, 1995; Michael \& Lindenmayer, 2012). A través del análisis de clasificación se observó que la heterogeneidad geomorfológica registrada en los afloramientos basálticos se relacionó con las tres comunidades vegetales discriminadas. En un extremo, se encuentran las Islas rocosas con cumbres planas a casi planas que se diferencian claramente de las formas circundantes (i.e., $\mathrm{MN}$ ), con pendientes pronunciadas. Este ambiente constituye el único hábitat rupícola propiamente dicho en el área de estudio, con predominio de matorrales dominados por las especies leñosas Flourensia campestris y Kageneckia lanceolata (i.e., Grupo 1) y Bromeliáceas casmófitas. En el otro extremo, se observa la Matriz Agrícola circundante, en la cual la cubierta vegetal original ha sido completamente modificada por la agricultura y la ganadería. En la actualidad esta comunidad se compone básicamente de hierbas anuales y perennes, muchas de ellas consideradas como malezas de cultivos y un menor número de representantes de la flora nativa. Fisonómicamente, se trata de herbazales abiertos dominados principalmente por Digitaria sanguinalis, Eleusine indica y Borreria spinosa (Grupo 3). La Matriz Natural representa una condición intermedia entre las Islas rocosas y la Matriz Agrícola, aunque no exhibe las características típicas de los afloramientos (i.e., grietas, fisuras, parches reducidos con acumulación de sedimentos, etc.), sino más bien las de una planicie fuertemente ondulada; por ello, carece de especies típicas de los hábitats rocosos (i.e., especies rupícolas). Las planicies onduladas están conformadas por un mosaico de pastizales y bosques bajos, cerrados, dominados alternativamente por arbustos como Acacia caven y Aloysia gratissima y por los pastos Aristida mendocina y Setaria leucopila (Grupo 2). En consecuencia, la gran heterogeneidad florística 


\section{J. J. Cantero et al. - Heterogeneidad de la vegetación en ambientes basálticos}

observada en una escala especial pequeña, resalta la importancia de la preservación de las Islas rocosas basálticas para la conservación del patrimonio natural de la provincia de Córdoba.

En un estudio previo de la vegetación de afloramientos basálticos a escala regional (varias provincias de Argentina), Cantero et al. (2016) adjudicaron las diferencias en composición a factores climáticos. En este estudio, los tres ambientes geomorfológicos explorados se encuentran bajo condiciones climáticas similares; por lo tanto, las diferencias reveladas por el análisis de clasificación podrían adjudicarse más bien a factores que actúan a escala local. Tanto efectos de la geoquímica sobre la composición florística (Wiser et al., 1996; Chiarucci et al., 2001; Grace et al., 2007; Tsiripidis et al., 2010), como así también diferencias locales en el tamaño y forma de los bloques rocosos (Wiser \& Buxton, 2009), han sido documentados como fuentes de variación de las comunidades de los roquedales. Considerando que las Islas rocosas relevadas en este estudio no exiben diferencias conspicuas en cuanto al tamaño y morfología de los bloques, las diferencias en composición registradas entre los dos subgrupos observados en ellas (i.e., 1.1 y 1.2) posiblemente respondan a la variabilidad en la composición química de los basaltos, especialmente en las concentraciones de $\mathrm{SiO}_{2}$ y $\mathrm{MgO}$. Además, análisis propios y otros reportados en la bibliografía (Lagorio, 2008), dan cuentas de diferencias en la concentración de $\mathrm{K}_{2} \mathrm{O}$, lo cual podría determinar cambios en la fertilidad (mayor en las mesadas ubicadas al sur del área de estudio) de los escasos sedimentos acumulados entre los bloques rocosos. Wiser \& Buxton (2009) han reportado cambios en la composición de las comunidades rocosas relacionados con variaciones en la fertilidad de estos ambientes. Cabido et al. (1990) y Funes \& Cabido (1995), trabajando en afloramientos graníticos de las Sierras de Córdoba, han reportado cambios florísticos importantes relacionados con variaciones locales en las características de los hábitats rocosos, con un alto recambio de especies en gradientes reducidos espacialmente. Además de los factores locales (i.e., química de las rocas, tamaño de los afloramientos y área disponible para las plantas, disturbios, etc.) mencionados por diversos autores (Cabido et al., 1990; Porembski et al., 1996; Wesche et al., 2005), Wiser \& Buxton
(2008) han advertido sobre la importante influencia que podría ejercer la composición de la vegetación de las áreas circundantes a los afloramientos. En las comunidades de los ambientes basálticos estudiados, éste podría ser un factor a considerar, ya que, como lo revela la tabla florística presentada, las Islas comparten numerosas especies con la Matriz Natural. De acuerdo con Wiser \& Buxton (2009), éste es un factor aún escasamente explorado en la bibliografía, el cual debería ser tenido en cuenta en próximos estudios que aborden la composición florística de afloramientos rocosos.

La riqueza y la diversidad de especies, como así también el número de especies exclusivas, fueron máximas en las islas rocosas y mínimas en la Matriz Agrícola, con valores intermedios en la Matriz Natural. A juzgar por estudios previos de la vegetación serrana en Córdoba (Giorgis et al., 2011), es posible suponer que los sitios ocupados actualmente por la Matriz Agrícola hayan sostenido en el pasado una composición florística y riqueza similar a la de las planicies onduladas de la Matriz Natural; lamentablemente, esa condición no es factible de ser encontrada en el área de estudio, ya que la agricultura, la ganadería y los incendios han removido casi totalmente la cubierta vegetal original sobre esas planicies (Giorgis et al., 2011). La mayor riqueza y diversidad de las Islas rocosas no puede ser atribuida a la heterogeneidad ambiental propia de esta geoforma, ya que exhiben una marcada homogeneidad en sus condiciones ecológicas, contrariamente a lo que puede observarse en la Matriz Natural. Es posible, entonces, que el gradiente de riqueza reportado en este estudio se relacione, más bien, con la intensidad y frecuencia de las perturbaciones que afectan a los paisajes basálticos: mientras las Islas rocosas son de dificil acceso para el ganado y el fuego, en la Matríz Natural se registran incendios frecuentes y en la Matriz agrícola ocurren las perturbaciones más severas (Cantero et al., 2016).

Las Islas rocosas y la Matriz Natural soportan no sólo una mayor riqueza y diversidad de especies, sino también una estructura mucho más compleja, como consecuencia de la presencia tanto de estratos leñosos (árboles y arbustos) como de pastos y otras hierbas. En general, la Matriz Agrícola carece actualmente de árboles y arbustos (a excepción de algunos individuos aislados de especies introducidas) y la vegetación está dominada por 
especies herbáceas anuales y perennes, muchas de ellas consideradas como malezas de cultivos. Similares patrones a los descriptos en este trabajo han sido reportados para otros ambientes rocosos de diferentes lugares del Mundo, donde la vegetación nativa que prospera sobre los mejores suelos (tal el caso de nuestra matriz circundante), ha sido erradicada para la agricultura (Prober \& Thiele, 2004). En el otro extremo, la vegetación de sitios inaccesibles y sobre suelos pobres (i.e, Islas rocosas), ha sobrevivido en condiciones relativamente intactas. En el sector intermedio del gradiente, la Matríz Natural, la agricultura no es posible pero están expuestas a perturbaciones como incendios, tala y extracción de leña y ganadería.

Otro aspecto que distingue a los afloramientos basálticos estudiados es el número de especies endémicas de rango local, regional y nacional. En total, el $14.3 \%$ de las $272 \mathrm{spp}$. registradas son endémicas, aunque la mayor parte de ellas lo son a nivel de todo el país (endémicas de rango nacional), mientras que el número de endémicas locales es bajo (Tabla 1). En afloramientos rocosos de otros lugares del Mundo, como por ej., California (Harrison et al., 2006), el Planalto brasilero (Torres Ribeiro et al., 2007), y Australia (Michael \& Lindenmayer, 2012), el porcentaje de especies endémicas a escala local es considerablemente más elevado. Posiblemente el grado de aislamiento que ofrecen nuestros ambientes basálticos no es tan marcado como el descripto por los autores citados. Las Islas rocosas constituyen los ambientes más ricos en endemismos (35), seguidos de la Matriz Natural (19), mientras el número es muy bajo en la Matriz Agrícola (3). Estos resultados no son sorprendentes, ya que los hallazgos realizados en otros afloramientos de distintos lugares del Mundo, confirman que los sitios más aislados suelen resguardar, a manera de refugios (Gram et al., 2004; Speziale \& Ezcurra, 2010), a plantas endémicas. Entre las especies endémicas a nivel nacional, algunas como Buddleja cordobensis, Cestrum parqui, Condalia microphylla, Metastelma tubatum, Microliabum candidum, Minthostachys verticillata, Nasssella cordobensis, Poa ligularis var. resinulosa, Proustia cuneifolia var. mendocina, Stevia satureiifolia var. satureiifolia, Trixis divaricata ssp. discolor, Zexmenia buphtalmiflora y, en especial Dyckia floribunda y Flourensia campestris, exhibieron valores de constancia superiores al $40 \%$ en alguna de las comunidades descriptas (Tabla 1). Contrariamente, entre las especies endémicas a nivel regional y/o local, sólo Sphaeralcea cordobensis mostró una constancia superior a ese valor, mientras que otras como Gymnocalycium bruchii var. bruchii, $G$. calochlorum, G. erinaceum y G. ochoterenae ssp. ochoterenae, además de su condición de endémicas locales, pueden considerarse como especies raras. Además de las especies endémicas, caracteriza la flora de las Islas rocosas un grupo importante de plantas de uso medicinal.

La proporción de corotipos registrada no se diferencia notablemente de la reportada por Cabido et al. (1998) para la vegetación de afloramientos de sectores bajos de las Sierras de Córdoba. Funes \& Cabido (1995) y Cabido et al. (1998) destacaron el efecto de la altitud en la distribución de corotipos en la flora de las Sierras de Córdoba. Estos autores señalan un límite biogeogeográfico a una altitud de aproximadamente $1700 \mathrm{~m}$ s.n.m., a partir del cual predomina el corotipo andino en la composición de la flora. Los ambientes explorados en este estudio se ubican entre 600 y 760 m s.n.m., lo cual no resulta en una altitud limitante para especies distribuidas ampliamente por el centro, norte y noreste de Argentina.

Los sitios menos perturbados exhiben un alto número de especies nativas y escasos taxones exóticos. Algunos autores (Fleischmann 1977; Meirelles et al., 1999) han calificado a los afloramientos rocosos como potentes filtros ambientales para las especies exóticas. Este parece también ser el caso de las Islas y la Matriz Natural, ya que el porcentaje de taxones adventicios es extremadamente bajo, en ambos casos menor al 4\%. Contrariamente, en la Matriz Agrícola numerosas hierbas exóticas parecen estar naturalizadas. En las Islas rocosas la relación nativas/exóticas es máxima (205/4), intermedia en la Matríz natural $(158 / 5)$ y mínima en la Matriz agrícola (36/19). Porembski (2000) y Porembski \& Barthlott (2000) han advertido la amenaza que representa este tipo de especies para la conservación de la flora de los inselbergs. Hay evidencias en la literatura que ponen de manifiesto que las especies exóticas pueden alterar la estructura de la vegetación y modificar los regímenes de incendios (Benwell, 2007), ocasionando la extinción de especies raras y endémicas características de los hábitats rocosos 


\section{J. J. Cantero et al. - Heterogeneidad de la vegetación en ambientes basálticos}

(Pigott, 2000). En este trabajo se registró un total de 24 spp. exóticas, la mayor parte de ellas malezas de cultivos pertenecientes a las familias de las Asteraceae y Poaceae. Si bien los ambientes menos alterados (Islas rocosas y Matriz Natural) registran un bajo número de exóticas, su proximidad a la Matriz Agrícola y la incidencia creciente de las perturbaciones, obligan a considerar especialmente las advertencias de Porembski (2000) y Pigott (2000). Algunas "malezas leñosas" registradas en este estudio en la Matriz Agrícola, como Ulmus pumila y Gleditsia triacanthos, han demostrado su potencialidad para invadir distintos ambientes en las sierras del centro del país, especialmente la segunda (Giorgis \& Tecco, 2014).

\section{Conclusiones}

En este trabajo examinamos la estructura y composición florística de la vegetación de paisajes basálticos (mesadas, conos y matriz circundante) en la provincia de Córdoba, centro de Argentina. En relación a las preguntas planteadas en este estudio puede concluirse que: 1) el patrón de distribución de las comunidades vegetales se asocia a las diferentes geoformas relevadas: el análisis de clasificación discrimina tres grupos principales de inventarios (comunidades) correspondientes respectivamente a las Islas rocosas, la Matriz Natural que las rodean y la Matriz Agrícola que circunda a los paisajes basálticos; esas comunidades están caracterizadas por especies diagnósticas; 2) las tres comunidades discriminadas difieren en su composición florística; 3) las mesadas y conos basálticos (i.e., Islas rocosas o inselbergs) son los sitios más ricos en especies, con mayor diversidad, mayor número de especies endémicas, y su fisonomía está dominada por formas arbustivas; en el otro extremo, la Matriz Agrícola es la más pobre en especies, la de menor diversidad y endemicidad, y predominan las hierbas perennes y anuales; 4) las Islas rocosas y la Matriz Natural registran bajos números de especies exóticas en su composición, mientras cerca del $50 \%$ de la flora de la Matriz Agrícola se compone de especies introducidas. En términos generales, los resultados de este estudio revelan la importancia de la preservación de las islas rocosas basálticas para la conservación del patrimonio natural de la provincia de Córdoba.

\section{Agradecimientos}

Este trabajo fue financiado por el Ministerio de Ciencia y Tecnología de la Provincia de Córdoba, la Secretaría de Ciencia y Tecnología de la Universidad Nacional de Río Cuarto, la Secretaría de Ciencia y Tecnología de la Universidad Nacional de Córdoba, la Secretaría de Minería de la Provincia de Córdoba.

\section{Bibliografía}

ALVES, R. \& J. KOLBEK. 1994. Plant-species endemism in savanna vegetation on Table Mountains (campo-rupestre) in Brazil. Vegetatio 113: 125-139.

BARTHLOTT, W. A., A. GREGER \& A. POREMBSKI. 1993. Some remarks on the vegetation of tropical inselbergs: Diversity and ecological differentiation. Biogeographica 69: 106-124.

BENWELL, A. 2007. Response of rock-outcrop and fringing vegetation to disturbance by fire and drought. Aust. J. Bot. 55: 736-748.

BIRKS, H. 2015. Some reflections on the refugium concept and its terminology in historical biogeography, contemporary ecology and globalchange biology. Biodiversity 16: 196-212.

BONALUMI, A., R. MARTINO, J. A. SFRAGULLA, C. CARIGNANO \& A. TAUBER. 2005. Hoja Geológica 3363-I Villa María, Provincia de Córdoba. Boletín 347. Instituto de Geología y Recursos Minerales. SEGEMAR, Buenos Aires.

BONALUMI, A., J. SFRAGULLA, D. JEREZ, S. BERTOLINO, J. SÁNCHEZ RIAL \& E. CARRIZO. 2014. Yacimientos de minerales y rocas industriales. In: MARTINO, R. D. \& A. B. GUERESCHI (eds.), Relatorio del XIX Congreso Geológico Argentino. Geología y recursos naturales de la Provincia de Córdoba, II, p. 983-1024. Córdoba.

BRADY, K. U., A. R. KRUCKEBERG \& H. D. BRADSHAW Jr. 2005. Evolutionary ecology of plant adaptation to serpentine soils. Ann. Rev. Ecol. Evol. Syst. 36: 243-266.

BRAUN-BLANQUET, J. 1979. Fitosociología. Bases para el estudio de las comunidades vegetales. Blume Ediciones, Madrid.

BURKE, A. 2002. Island-matrix relationships in Nama Karoo inselberg landscapes. Part I: do inselbergs provide a refuge for matrix species? Plant Ecol. 160: 79-90.

BURKE, A., K. ESLER, E. PIENAAR \& P. BARNARD. 2003. Species richness and floristic relationships between mesas and their surroundings in southern African Nama Karoo. Divers. Distrib. 9: 43-53. 
CABIDO, M., A. ACOSTA \& S. DÍAZ. 1990. The vascular flora and vegetation of granitic outcrops in the upper Córdoba mountains. Argentina. Phytocoenologia 19: 267-281.

CABIDO, M., G. FUNES, E. PUCHETA, F. VENDRAMINI \& S. DÍAZ. 1998. A chorological analysis of the mountains from Central Argentina. Is all what we call Sierra Chaco really Chaco? Candollea 53: 321-331.

CABRERA, A. 1976. Regiones fitogeográficas argentinas. 2da ed. Enciclopedia Argentina de Agricultura y Jardinería. ACME, Buenos Aires.

CÁCERES, D. M., E. TAPELLA, F. QUÉTIER \& S. DÍAZ. 2015. The social value of biodiversity and ecosystem services from the perspectives of different social actors. Ecol. Soc. 20: 62.

CANTERO, J. J., C. NÚÑEZ, J. MULKO, P. BRANDOLÍN, A. AMUCHASTEGUI, J. SFRAGULlA, A. BONALUMI, A. MARTINEZ, S. ZEBALLOS, M. CABIDO, G. BARBOZA, F. CHIARINI \& L. ARIZA ESPINAR. 2016. Vegetación y flora de afloramientos basálticos del centro de Argenina. Arnaldoa 23: 185 218.

CANTERO, J. J., J. A. SFRAGUlla, C. NÚÑEZ, A. BONALUMI, J. MULKO, A. AMUCHASTEGUI, F. CHIARINI, G. E. BARBOZA \& L. ARIZA ESPINAR. 2011. Flora de los afloramientos de mármoles y serpentinitas de las Sierras de Córdoba (Argentina). Kurtziana 36: 11-45.

CANTÚ, M. 1992. Holoceno de la Provincia de Córdoba. In: Iriondo, M. (ed.), El Holoceno en la Argentina, p. 1-16. Editorial CADINQUA, Paraná.

CARIGNANO, C. 1997. Caracterización y evolución durante el Cuaternario Superior de los ambientes geomorfológicos extraserranos en el noroeste de la provincia de Córdoba. Tesis Doctoral Inédita. Facultad de Ciencias Exactas Físicas y Naturales. Universidad Nacional de Córdoba, Argentina.

ČERNÝ, T., M. KOPECKÝ, P. PETŘIK, J. SONG, M. ŠRŮTEK, M. VALACHOVIČ, J. ALTMAN \& J. DOLEŽAL. 2015. Classification of Korean forests: patterns along geographic and environmental gradients. Appl. Veg. Sci. 18: 5-22.

CLARKE, P. J. 2002. Habitat islands in fire-prone vegetation: do landscape features influence community composition? J. Biogeogr. 29: 677-684.

CONCEIÇÃO, A., F. CRISTO, A. DOS SANTOS, J. DOS SANTOS, E. FREITAS, B. DOS SANTOS BORGES, L. MACÊDO \& R. DA SILVA OLIVEIRA. 2015. Vegetação endêmica e espécie invasora em campos rupestres de áreas garimpadas. Rodriguésia 66: 675683.

CHIAPELLA, J. \& P. H. DEMAIO. 2015. Plant endemism in the Sierras of Córdoba and San Luis (Argentina): understanding links between phylogeny and regional biogeographical patterns. PhytoKeys 47: 59-96.
CHIARUCCI, A., D. ROCCHINI, C. LEONZIO \& V. DE DOMINICIS. 2001. A test of vegetationenvironment relationship in serpentine soils of Tuscany, Italy. Ecol. Res. 16: 627-639.

DÍAZ, S., S. DEMISSEW, J. CARABIAS, C. JOLY, M. LONSDALE, N. ASH, A. LARIGAUDERIE, J. RAM ADHIKARI, S. ARICO, A. BALDI A et al. 2015: The IPBES Conceptual Framework connecting nature and people. Curr. Opin. Environ. Sustain. 14: 1-16.

DI RIENZO, J. A., F. CASANOVES, M. G. BALZARINI, L. GONZALEZ, M. TABLADA \& C. W. ROBLEDO. 2011. InfoStat versión 2011. Grupo InfoStat, Facultad de Ciencias Agropecuarias, Universidad Nacional de Córdoba, Argentina. http:// www.infostat.com.ar.

FINGER, A., S. STOLTON \& N. DUDLEY (eds.). 1999. Metals from the forests: mining and forest degradation. Arborvitae, special issue. World Wide Fund for Nature \& International Union for Conservation of Nature, Gland.

FLEISCHMANN, K. 1997. Invasion of alien woody plants on the islands of Mahé and Silhouette, Seychelles. J. Veg. Sci. 8: 5-12.

FUNES, G. \& M. CABIDO. 1995. Variabilidad local y regional de la vegetación rupícola de las Sierras Grandes de Córdoba, Argentina. Kurtziana 24: $173-$ 188.

GIBSON, N., C. J. YATES \& R. DILLON. 2010. Plant communities of the ironstone ranges of South Western Australia: Hotspots for plant diversity and mineral deposits. Biodiver. Conserv. 19: 3951-3962.

GINOCCHIO, R. \& A. J. M. BAKER. 2004. Metallophytes in Latin America: a remarkable biological and genetic resource scarcely known and studied in the region. Revista Chil. Hist. Nat. 77: 185-194.

GIORGIS, M., A. CINGOLANI, F. CHIARINI, J. CHIAPELLA, G. BARBOZA., L. ARIZA ESPINAR, R. MORERO, D. GURVICH, P. TECCO, R. SUBILS \& M. CABIDO. 2011. Composición florística del Bosque Chaqueño Serrano de la provincia de Córdoba, Argentina. Kurtziana 36: 9-43.

GIORGIS, M. A. \& P. A. TECCO. 2014. Árboles y arbustos invasores de la provincia de Córdoba (Argentina): una contribución a la sistematización de bases de datos globales. Bol. Soc. Argent. Bot. 49: 581-603.

GIULIETTI, A. M., R. M. HARLEY, L. P. DE QUEIROZ, M. G. L. WANDERLEY \& C. VAN DEN BERG. 2005. Biodiversity and conservation of plants in Brazil. Conserv. Biol. 19: 632-639.

GOMES, P. \& M. ALVES. 2009. Floristic and vegetational aspects of an inselberg in the semi-arid region of Northeast Brazil. Edinb. J. Bot. 66:1-18. 


\section{J. J. Cantero et al. - Heterogeneidad de la vegetación en ambientes basálticos}

GOMES, P. \& M. ALVES. 2010. Floristic diversity of two crystalline rocky outcrops in the Brazilian northeast semi-arid region. Revista Bras. Bot. 33: 661-676.

GORDILLO, C. E. \& A. LENCINAS. 1967. Geología y petrología del extremo norte de la Sierra de Los Cóndores, Córdoba. Bol. Acad. Nac. Ci. Córdoba 46: 73-108.

GORDILLO, C. E. \& A. LENCINAS. 1979. Sierras Pampeanas de Córdoba y San Luis. In: LEANZA, A. P. (ed.), Geología Regional Argentina. Academia Nacional de Ciencias, Córdoba, Argentina, 1: 577650.

GRACE, J., H. SAVORD \& S. HARRISON. 2007. Largescale causes of variation in the serpentine vegetation of California. Plant Soil 293: 121-132.

GRAM, W., E. BORER, K. COTTINGHAM, E. SEABLOOM, V. BOUCHER, L. GOLDWASSER, F. MICHELI, B. KENDALL \& R. BURTON. 2004. Distribution of plants in a California serpentine grassland: are rocky hummocks spatial refuges for native species? Plant Ecol. 172: 159-171.

HARRISON, S., H. D. SAFFORD, J. B. GRACE, J. H. VIERS \& K. F. DAVIES. 2006. Regional and local species richness in an insular environment: serpentine plants in California. Ecol. Monogr. 76: 41-56.

HIJMANS, R. J., S. CAMERON, J. PARRA, P. G. JONES, A. JARVIS \& K. RICHARDSON. (2005). WorldClim_-global climate data. Very High Resolution Interpolated Climate Surfaces for Global Land Areas. http://www.worldclim.org/tiles.php.

JACOBI, C. M. \& F. F. DO CARMO. 2008a. Diversidade dos campos rupestres ferruginosos no Quadrilátero Ferrífero, MG. Megadiversidade 4: 25-33.

JACOBI, C. M. \& F. F. DO CARMO. 2008b. The contribution of ironstone outcrops to plant diversity in the Iron Quadrangle, a threatened Brazilian landscape. Ambio 37: 324-326.

JACOBI, C. M., F. F. DO CARMO \& I. A. CAMPOS. 2011. Soaring Extinction Threats to Endemic Plants in Brazilian Metal-Rich Regions. Ambio 40: 540-543.

JACOBI, C. M., F. F. CARMO, R. C. VINCENT \& J. STEHMANN. 2007. Plant communities on ironstone outcrops - a diverse and endangered Brazilian ecosystem. Biodivers. Conserv. 16: 2185-2200.

KAY, S. M. \& V. A. RAMOS. 1996. El magmatismo cretácico de las Sierras de Córdoba y sus implicancias tectónicas. En $13^{\circ}$ Congreso Geológico Argentino y $3^{\circ}$ Congreso Exploración de Hidrocarburos, Actas 3: 404. Buenos Aires.

LAGORIO, S. L. 1998. Geoquímica y petrogénesis de volcanitas cretácicas de la Sierra Chica de Córdoba (Argentina). En $10^{\circ}$ Congreso Latinoamericano de Geología y $6^{\circ}$ Congreso Nacional de Geología Económicap, p. 354-358. Buenos Aires.
LAGORIO, S. L. 2008. Early Cretaceous alkaline volcanism of the Sierra Chica de Córdoba (Argentina): mineralogy, geochemistry and petrogenesis. J. S. Am. Earth Sci. 26: 152-171.

LAGORIO, S. L., H. VIZÁN \& S. E. GEUNA.2014. El volcanismo alcalino cretácico. In: MARTINO, R. D. \& A. B. GUERESCHI (eds.): Geología y Recursos Naturales de la Provincia de Córdoba. $19^{\circ}$ Congreso Geológico Argentino, Relatorio I, p. 473511. Córdoba.

LLAMBÍAS, E. J. \& N. BROGIONI. 1981. Magmatismo Mesozoico y Cenozoico. En M. Yrigoyen (eds.), Geología y Recursos Naturales de la provincia de San Luis. Relatorio VIII Congreso Geológico Argentino, p. 101-115. San Luis.

McCUNE, B. \& M. MEFFORD. 1999. Multivariate Analysis of Ecological Data, Version 4.0. MjM Software, Gleneden Beach.

MEIRELLES, T. S., V. R. PIVELLO \& C. A. JOLY. 1999. The vegetation of granite rock outcrops in Rio de Janeiro, Brazil, and the need for its protection. Environ. Conserv. 26: 10-20.

MICHAEL, D. R. \& D. B. LINDENMAYER. 2012. Vegetation structure and floristics of granite landforms in the South-west Slopes of New South Wales. Cunninghamia 12: 309-323.

MICHELANGELI, F. A. 2000. Species composition and species-area relationships in vegetation isolates on summit of a sandstone mountain in southern Venezuela. J. Trop. Ecol. 16: 69-82.

MILCHUNAS, D. G. \& I. NOY-MEIR. 2002. Grazing refuges, external avoidance of herbivory and plant diversity. Oikos 99: 113-130.

NORRIS, E. H. \& J. THOMAS. 1991. Vegetation on rocky outcrops and ranges in central and south-western New South Wales. Cunninghamia 2: 411-441.

ORTIZ, S. \& J. RODRÍGUEZ OUBIÑA. 1993. Synopsis of the rupicolous vegetation of Galicia (North-western Iberian Peninsula). Folia Geobot. Phytotax. 28: 15-49.

PIGOTT, J. P. 2000. Environmental weeds and granite outcrops: possible solutions in the "too hard basket"? J. Roy. Soc. W. Aust. 83: 135-137.

POREMBSKI, S. 2000. The invasibility of tropical granite outcrops ('inselbergs') by exotic weeds. J. Roy. Soc. W. Aust. 83: 131-137.

POREMBSKI, S. \& W. BARTHLOTT (eds.). 2000. Inselbergs: biotic diversity of isolated rock outcrops in tropical and temperate regions. Ecological studies146, Springer-Verlag, Heidelberg, Germany.

POREMBSKI, S., W. BARTHLOTT, S. DÖRRSTOCK \& N. BIEDINGER. 1994. Vegetation of rock outcrops in Guinea: granite inselbergs, sandstone table mountains and ferricretes - remarks on species numbers and endemism. Flora 189: 315-326. 
POREMBSKI, S., J. SZARZYNSKI, J. P. MUND \& W. BARTHLOTT. 1996. Biodiversity and vegetation of small-sized inselbergs in a West African rain forest (Taï, Ivory Coast). J. Biogeogr. 23: 47-55.

POZO P., J. WOOD, D. SOTO \& S. BECK. 2013. Plantas Endémicas de Afloramientos Rocosos en las Serranías de Roboré y Concepción: Implicaciones para su Conservación. Revista Soc. Bol. Bot. 7: 7381.

PROBER, S. M. \& K. R. THIELE. 2004. Floristic patterns along an east-west gradient in grassy box woodlands of Central New South Wales. Cunninghamia 8: 306-325.

R Core Team. 2014. R: A language and environment for statistical computing. R Foundation for Statistical Computing, Vienna, Austria. http://www.R-project. org/

REZENDE, L. 2013. Restauração ecológica de Campos rupestres ferruginosos. Tese doutoral, Universidade Federal de Viçosa, Minas Gerais, Brasil.

SCHMIDTLEIN, S., L. TICHÝ, H. FEILHAUER \& U. FAUDE. 2010. A brute-force approach to vegetation classification. J. Veg. Sci. 21: 1162-1171.

SMITH, J. M. B. \& A. M. CLEEF. 1988. Composition and origins of the world's tropical pine floras. J. Biogeogr. 15: 631-645.

SPEZIALE, K. L. \& C. EZCURRA. 2012. The role of outcrops in the diversity of Patagonian vegetation: relicts of glacial palaeofloras? Flora 207: 141-149.

VAN DER MAAREL, E. 1979. Transformation of coverabundance values in phytosociology and its effects on community similarity. Vegetatio 39: 97-114.

TENENBAUM, J. B., V. DE SILVA \& J. C. LANGFORD. 2000. A global geometric framework for nonlinear dimensionality reduction. Science 290: 2319-2323.

TORRES RIBEIRO, K., B. M. OPAZO MEDINA, \& F.R. SCARANO. 2007. Species composition and biogeographic relations of the rock outcrop flora on the high palteau of Itatiaia, SE-Brazil. Revista Bras. Bot. 30: 623-639.

TSIRIPIDIS, I., A. PAPAIOANNOU, V. SAPOUNIDIS \& E. BERGMEIER. 2010. Approaching the serpentine factor at a local scale -a study in an ultramafic area in northern Greece. Plant Soil 329: 35-50.

WATSON, P. \& G. WARDELL-JOHNSON. 2004. Fire frequency and time-since-fire effects on the openforest and woodland flora of Girraween National Park, south-east Queensland, Australia. Austral Ecol. 29: 225-236.
WESCHE, K., M. PARTZSCH, S. KREBES \& I. HENSEN. 2005. Gradients in dry grassland and heath vegetation on rock outcrops in eastern Germany - An analysis of a large phytosociological data set. Folia Geobot. 40: 341-356.

WISER, S. K. \& R. P. BUXTON. 2008. Context matters: Matrix vegetation influences native and exotic species composition on habitat islands. Ecology 89: 380-391.

WISER, S. K. \& R. P. BUXTON. 2009. Montane outcrop vegetation of Banks Peninsula, South Island, New Zealand. N. Z. J. Ecol. 33: 164-176.

WISER, S. K., R. K. PEET \& P. S. WHITE. 1996. Highelevation rock outcrop vegetation of the Southern Appalachian Mountains. J. Veg. Sci. 7: 703-722.

ZULOAGA, F. O. \& O. MORRONE. 1999a. Catálogo de las Plantas Vasculares de la República Argentina. I. Monogr. Syst. Bot. Missouri Bot. Gard. 60: 1-323.

ZULOAGA, F. O. \& O. MORRONE. 1999b. Catálogo de las Plantas Vasculares de la República Argentina. II. Monogr. Syst. Bot. Missouri Bot. Gard. 74: 1-1269.

ZULOAGA, F. O., O. MORRONE \& M. J. BELGRANO. 2008. Catálogo de Las Plantas Vasculares del Cono Sur: (Argentina, Sur de Brasil, Chile, Paraguay y Uruguay). (I-II-III) Monogr. Syst. Bot. Missouri Bot. Gard. 107: 1-3348.

ZULOAGA, F. O., E. G. NICORA, Z. RÚGOLO DE AGRASAR, O. MORRONE, J. PENSIERO \& A. M. CIALDELLA. 1994. Catálogo de la Familia Poaceae en la República Argentina. Monogr. Syst. Bot. Missouri Bot. Gard. 47: 1-178.

Recibido el 01 de agosto de 2016, aceptado el 26 de diciembre de 2016. 


\section{J. J. Cantero et al. - Heterogeneidad de la vegetación en ambientes basálticos}

Apéndice. Listado de las especies de plantas vasculares relevadas en afloramientos basálticos y matrices circundantes de la Sierra de Los Cóndores (Córdoba, Argentina), ordenadas en sus correspondientes familias. Abreviaturas. Status: Nat, especies nativas; Exo, especies exóticas. Especies endémicas: $\mathrm{N}$, endémicas de todo el país; $\mathrm{R}$, endémicas de la region; $L$, endémicas solo de la provincia de Córdoba. Formas de vida: árboles $(A)$, arbustos (Ar), arbustos parásitos $(\mathrm{Ap})$, bromeliáceas rupícolas $(\mathrm{Br})$, cactáceas columnares $(\mathrm{Cc})$, cactáceas globulares $(\mathrm{Cg})$, cactáceas opuntioides (Co), enredaderas (En), epífitas (Ep), hierbas anuales (Ha), helechos (HE), hierbas perennes caducifolias (Hpc), hierbas perennes siempre-verdes (Hps), gramíneas $(\mathrm{G})$, graminoides $(\mathrm{Gr})$, gramíneas en mata $(\mathrm{Gm})$, parásitas $(\mathrm{P})$. Afloramientos rocosos: IR, Islas rocosas; MN, Matríz Natural; MA, MAtriz Agrícola. Grupos corológicos (C): A, Andino; $\mathrm{CH}$, Chaqueño; CMP, Cosmopolitas; E, Exóticas; MB, Orófilo Bajo (Montañas bajas del centro y oeste de Argentina); AB, Austrobrasilero; $\mathrm{P}$, Patagónico.

\begin{tabular}{|c|c|c|c|c|c|c|c|c|c|c|c|}
\hline \multirow{3}{*}{ Especie } & \multirow{3}{*}{ Familia } & \multirow{3}{*}{ Nat } & \multicolumn{4}{|c|}{ Status } & \multirow{3}{*}{ FdV } & \multirow{2}{*}{\multicolumn{3}{|c|}{ Afloramientos }} & \multirow{3}{*}{ C } \\
\hline & & & \multirow{2}{*}{ Exo } & \multicolumn{3}{|c|}{ Endemica } & & & & & \\
\hline & & & & $\mathbf{N}$ & $\mathbf{R}$ & $\mathbf{L}$ & & IR & MN & MA & \\
\hline Dicliptera scutellata Griseb. & Acanthaceae & $\mathrm{X}$ & & & & & Hps & $x$ & $x$ & & MB \\
\hline Dyschoriste humilis Lindau & Acanthaceae & $\mathrm{x}$ & & & & & Hps & $x$ & & & $\mathrm{CH}$ \\
\hline Stenandrium dulce (Cav.) Nees & Acanthaceae & $x$ & & & & & Hps & $x$ & $x$ & & $\mathrm{CH}$ \\
\hline $\begin{array}{l}\text { Nothoscordum gracile (Dryand. ex Aiton) } \\
\text { Stearn var. gracile }\end{array}$ & Alliaceae & $\mathrm{X}$ & & & & & $\mathrm{Gr}$ & $x$ & & & $A B$ \\
\hline Amaranthus hybridus L. ssp. hybridus & Amaranthaceae & & $\mathrm{x}$ & & & & $\mathrm{Ha}$ & $x$ & & & $E$ \\
\hline Amaranthus standleyanus Parodi ex Covas & Amaranthaceae & $\mathrm{x}$ & & & & & $\mathrm{Ha}$ & & $\mathrm{X}$ & $\mathrm{X}$ & $\mathrm{CH}$ \\
\hline Gomphrena perennis L. var. perennis & Amaranthaceae & $\mathrm{X}$ & & & & & $\mathrm{Hpc}$ & $x$ & $\mathrm{X}$ & & $A B$ \\
\hline $\begin{array}{l}\text { Gomphrena pulchella Mart. ssp. rosea } \\
\text { (Griseb.) Pedersen }\end{array}$ & Amaranthaceae & $\mathrm{X}$ & & $\mathrm{X}$ & & & Нрс & $\mathrm{X}$ & & & $\mathrm{AB}$ \\
\hline $\begin{array}{l}\text { Iresine diffusa Humb. \& Bonpl. ex Willd. var. } \\
\text { diffusa }\end{array}$ & Amaranthaceae & $X$ & & & & & Hps & $\mathrm{X}$ & $\mathrm{X}$ & & $\mathrm{AB}$ \\
\hline Pfaffia gnaphaloides (L. f.) Mart. & Amaranthaceae & $\mathrm{X}$ & & & & & Hps & $\mathrm{x}$ & $\mathrm{X}$ & & $\mathrm{CH}$ \\
\hline Zephyranthes filifolia Herb. ex Kraenzl. & Amaryllidaceae & $\mathrm{X}$ & & $X$ & & & $\mathrm{Gr}$ & $x$ & & & $A B$ \\
\hline Lithraea molleoides (Vell.) Engl. & Anacardiaceae & $\mathrm{X}$ & & & & & $A$ & $x$ & & & MB \\
\hline $\begin{array}{l}\text { Schinus fasciculatus (Griseb.) I.M. Johnst. } \\
\text { var. fasciculatus }\end{array}$ & Anacardiaceae & $\mathrm{X}$ & & & & & $A$ & $X$ & $\mathrm{X}$ & $\mathrm{X}$ & $A B$ \\
\hline Bowlesia incana Ruiz \& Pav. & Apiaceae & & $\mathrm{X}$ & & & & $\mathrm{Ha}$ & & & $\mathrm{x}$ & $A B$ \\
\hline $\begin{array}{l}\text { Cyclospermum leptophyllum (Pers.) Sprague } \\
\text { var. leptophyllum }\end{array}$ & Apiaceae & $\mathrm{X}$ & & & & & $\mathrm{Ha}$ & & & $x$ & $\mathrm{AB}$ \\
\hline Eryngium horridum Malme & Apiaceae & $\mathrm{X}$ & & & & & Hps & $x$ & & $\mathrm{X}$ & $A B$ \\
\hline $\begin{array}{l}\text { Araujia brachystephana (Griseb.) Fontella \& } \\
\text { Goyder }\end{array}$ & Apocynaceae & $X$ & & & & & En & & $\mathrm{X}$ & & $\mathrm{AB}$ \\
\hline $\begin{array}{l}\text { Araujia odorata (Hook. \& Arn.) Fontella \& } \\
\text { Goyder }\end{array}$ & Apocynaceae & $x$ & & & & & En & & & $x$ & $A B$ \\
\hline Mandevilla laxa (Ruiz \& Pav.) Woodson & Apocynaceae & $\mathrm{X}$ & & & & & En & $x$ & & & $A B$ \\
\hline Mandevilla pentlandiana (A. DC.) Woodson & Apocynaceae & $x$ & & & & & En & $x$ & $x$ & & $A B$ \\
\hline Metastelma tubatum Griseb. & Apocynaceae & $x$ & & $x$ & & & En & $x$ & $x$ & & $\mathrm{AB}$ \\
\hline Philibertia gilliesii Hook. \& Arn. & Apocynaceae & $x$ & & & & & En & $x$ & $x$ & & $\mathrm{CH}$ \\
\hline Asplenium monanthes $\mathrm{L}$. & Aspleniaceae & $\mathrm{X}$ & & & & & $\mathrm{H}$ & $X$ & $x$ & & $A$ \\
\hline $\begin{array}{l}\text { Acanthostyles buniifolius (Hook. \& Arn.) R.M. } \\
\text { King \& H. Rob. }\end{array}$ & Asteraceae & $x$ & & & & & $\mathrm{Ar}$ & $x$ & $x$ & & $\mathrm{CH}$ \\
\hline Achyrocline alata (Kunth) DC. & Asteraceae & $x$ & & & & & $\mathrm{Ar}$ & $x$ & & & $\mathrm{CH}$ \\
\hline Achyrocline satureioides (Lam.) DC. & Asteraceae & $x$ & & & & & $\mathrm{Ar}$ & $x$ & & & $\mathrm{CH}$ \\
\hline
\end{tabular}




\begin{tabular}{|c|c|c|c|c|c|c|c|c|c|c|}
\hline \multirow{3}{*}{ Especie } & \multirow{3}{*}{ Familia } & \multirow{3}{*}{ Nat } & \multicolumn{3}{|c|}{ Status } & \multirow{3}{*}{ FdV } & \multirow{2}{*}{\multicolumn{3}{|c|}{ Afloramientos }} & \multirow{3}{*}{ C } \\
\hline & & & \multirow{2}{*}{ Exo } & \multicolumn{2}{|c|}{ Endemica } & & & & & \\
\hline & & & & $\mathbf{N}$ & $\mathbf{R} \quad \mathbf{L}$ & & IR & MN & MA & \\
\hline $\begin{array}{l}\text { Acmella decumbens (Sm.) R.K. Jansen var. } \\
\text { decumbens }\end{array}$ & Asteraceae & $x$ & & & & Hps & $x$ & & & $A B$ \\
\hline Angelphytum aspilioides (Griseb. H. Rob. & Asteraceae & $\mathrm{x}$ & & $\mathrm{x}$ & & $\mathrm{Ar}$ & $\mathrm{x}$ & $\mathrm{x}$ & & $\mathrm{CH}$ \\
\hline $\begin{array}{l}\text { Austrobrickellia patens (D. Don ex Hook. \& } \\
\text { Arn.) R.M. King \& H. Rob. }\end{array}$ & Asteraceae & $x$ & & & & En & & $x$ & & $\mathrm{MB}$ \\
\hline Baccharis coridifolia DC. & Asteraceae & $x$ & & & & $\mathrm{Ar}$ & $\mathrm{X}$ & $x$ & & $A B$ \\
\hline Baccharis flabellata Hook. \& Arn. & Asteraceae & $\mathrm{x}$ & & & $\mathrm{x}$ & $\mathrm{Ar}$ & $\mathrm{x}$ & & & $\mathrm{CH}$ \\
\hline Baccharis glutinosa Pers. & Asteraceae & $x$ & & & & $\mathrm{Ar}$ & $x$ & $x$ & & MB \\
\hline Baccharis sessiliflora Vahl & Asteraceae & $x$ & & & & $\mathrm{Ar}$ & $x$ & & & $\mathrm{CH}$ \\
\hline Baccharis stenophylla Ariza & Asteraceae & $x$ & & & & Hps & & $x$ & & $\mathrm{CH}$ \\
\hline Baccharis ulicina Hook. \& Arn. & Asteraceae & $x$ & & & & $\mathrm{Ar}$ & $x$ & $x$ & & $A B$ \\
\hline Bidens pilosa L. var. pilosa & Asteraceae & $x$ & & & & $\mathrm{Ha}$ & $x$ & $x$ & & $A B$ \\
\hline Bidens subalternans DC. var. subalternans & Asteraceae & $x$ & & & & $\mathrm{Ha}$ & $\mathrm{x}$ & $x$ & $x$ & $A B$ \\
\hline Carduus acanthoides L. & Asteraceae & & $\mathrm{x}$ & & & $\mathrm{Ha}$ & & & $\mathrm{x}$ & $\mathrm{E}$ \\
\hline Chaptalia integerrima (Vell.) Burkart & Asteraceae & $x$ & & & & Hps & $\mathrm{x}$ & $x$ & & $\mathrm{MB}$ \\
\hline $\begin{array}{l}\text { Chromolaena arnottiana (Griseb.) R.M. King } \\
\text { \& H. Rob. }\end{array}$ & Asteraceae & $x$ & & & & Hps & $x$ & $x$ & & $\mathrm{CH}$ \\
\hline $\begin{array}{l}\text { Conyza bonariensis (L.) Cronquist var. } \\
\text { bonariensis }\end{array}$ & Asteraceae & $x$ & & & & $\mathrm{Ha}$ & $x$ & & $x$ & $A B$ \\
\hline Flourensia campestris Griseb. & Asteraceae & $x$ & & $x$ & & $\operatorname{Ar}$ & $\mathrm{X}$ & & & MB \\
\hline Galinsoga parviflora Cav. & Asteraceae & $\mathrm{x}$ & & & & $\mathrm{Ha}$ & & & $\mathrm{x}$ & $A B$ \\
\hline Gamochaeta filaginea (DC.) Cabrera & Asteraceae & $x$ & & $x$ & & $\mathrm{Ha}$ & $\mathrm{x}$ & & & $A B$ \\
\hline $\begin{array}{l}\text { Gyptis artemisifolia (Griseb.) R.M. King \& H. } \\
\text { Rob. }\end{array}$ & Asteraceae & $x$ & & & $x$ & Hps & $x$ & & & $A B$ \\
\hline Heterosperma ovatifolium Cav. & Asteraceae & $x$ & & & & $\mathrm{Ha}$ & $x$ & $x$ & & $A B$ \\
\hline Heterosperma tenuisectum (Griseb.) Cabrera & Asteraceae & $\mathrm{x}$ & & & & $\mathrm{Ha}$ & & $\mathrm{x}$ & & $\mathrm{CH}$ \\
\hline Hysterionica jasionoides Willd. & Asteraceae & $\mathrm{x}$ & & & & Hps & $\mathrm{x}$ & $\mathrm{x}$ & & $\mathrm{CH}$ \\
\hline $\begin{array}{l}\text { Lorentzianthus viscidus (Hook. \& Arn.) R.M. } \\
\text { King \& H. Rob. }\end{array}$ & Asteraceae & $x$ & & & & $\mathrm{Ar}$ & $x$ & $x$ & & $\mathrm{CH}$ \\
\hline Microgyne trifurcata Less. & Asteraceae & $x$ & & & & $\mathrm{Hpc}$ & & $x$ & & $A B$ \\
\hline Microliabum candidum (Griseb.) H. Rob. & Asteraceae & $x$ & & $x$ & & $\mathrm{Hpc}$ & $x$ & & & $\mathrm{CH}$ \\
\hline Parthenium hysterophorus L. & Asteraceae & $\mathrm{x}$ & & & & $\mathrm{Hpc}$ & $\mathrm{X}$ & $\mathrm{x}$ & & $A B$ \\
\hline $\begin{array}{l}\text { Proustia cuneifolia D. Don var. mendocina } \\
\text { (Phil.) Ariza }\end{array}$ & Asteraceae & $\mathrm{x}$ & & $\mathrm{x}$ & & $\mathrm{Ar}$ & $\mathrm{x}$ & $\mathrm{x}$ & & $\mathrm{CH}$ \\
\hline Schkuhria pinnata (Lam.) Kuntze ex Thell. & Asteraceae & $x$ & & & & $\mathrm{Ha}$ & & $x$ & & $A B$ \\
\hline Simsia dombeyana DC. & Asteraceae & $x$ & & & & $\mathrm{Hpc}$ & $x$ & $x$ & & $\mathrm{CH}$ \\
\hline Solidago chilensis Meyen var. chilensis & Asteraceae & $\mathrm{x}$ & & & & $\mathrm{Hpc}$ & $\mathrm{X}$ & & & $A B$ \\
\hline Sonchus asper $\mathrm{L}$. & Asteraceae & & $\mathrm{x}$ & & & $\mathrm{Ha}$ & & & $\mathrm{x}$ & $\mathrm{E}$ \\
\hline
\end{tabular}




\begin{tabular}{|c|c|c|c|c|c|c|c|c|c|c|c|}
\hline \multirow{3}{*}{ Especie } & \multirow{3}{*}{ Familia } & \multirow{3}{*}{ Nat } & \multicolumn{4}{|c|}{ Status } & \multirow{3}{*}{ FdV } & \multirow{2}{*}{\multicolumn{3}{|c|}{ Afloramientos }} & \multirow{3}{*}{ C } \\
\hline & & & \multirow{2}{*}{ Exo } & \multicolumn{3}{|c|}{ Endemica } & & & & & \\
\hline & & & & $\mathbf{N}$ & $\mathbf{R}$ & $\mathbf{L}$ & & IR & MN & MA & \\
\hline Sonchus oleraceus L. & Asteraceae & & $x$ & & & & $\mathrm{Ha}$ & $x$ & & $x$ & E \\
\hline $\begin{array}{l}\text { Stevia satureiifolia (Lam.) Sch. Bip. ex } \\
\text { Klotzsch var. satureiifolia }\end{array}$ & Asteraceae & $x$ & & $x$ & & & Hps & $x$ & $x$ & & $A B$ \\
\hline Tagetes minuta L. & Asteraceae & $x$ & & & & & $\mathrm{Ha}$ & $x$ & $x$ & & $A B$ \\
\hline $\begin{array}{l}\text { Trixis divaricata (Kunth) Spreng. ssp. discolor } \\
\text { (D. Don) Katinas }\end{array}$ & Asteraceae & $\mathrm{x}$ & & $\mathrm{x}$ & & & Hps & $\mathrm{x}$ & $\mathrm{x}$ & & $\mathrm{CH}$ \\
\hline $\begin{array}{l}\text { Vernonanthura nudiflora (Less.) H. Rob. f. var. } \\
\text { nudiflora }\end{array}$ & Asteraceae & $x$ & & & & & Hps & $x$ & $x$ & & $A B$ \\
\hline Xanthium spinosum L. var. spinosum & Asteraceae & $x$ & & & & & $\mathrm{Ha}$ & & $x$ & & $A B$ \\
\hline Xanthium strumarium L. & Asteraceae & $x$ & & & & & $\mathrm{Ha}$ & & & $x$ & $A B$ \\
\hline Zexmenia buphtalmiflora (Lorentz) Ariza & Asteraceae & $x$ & & $x$ & & & Hps & $x$ & & & $A B$ \\
\hline Zinnia peruviana (L.) L. & Asteraceae & $x$ & & & & & $\mathrm{Ha}$ & $x$ & $x$ & & $\mathrm{CH}$ \\
\hline Anredera cordifolia (Ten.) Steenis & Basellaceae & $\mathrm{x}$ & & & & & En & $x$ & $\mathrm{x}$ & & $\mathrm{CH}$ \\
\hline $\begin{array}{l}\text { Amphilophium carolinae (Lindl.) L. G. } \\
\text { Lohmann }\end{array}$ & Bignoniaceae & $\mathrm{x}$ & & & & & En & $\mathrm{x}$ & $\mathrm{x}$ & & MB \\
\hline Dolichandra cynanchioides Cham. & Bignoniaceae & $\mathrm{x}$ & & & & & En & $x$ & & & MB \\
\hline Heliotropium campestre Griseb. & Boraginaceae & $x$ & & & & & Hps & $x$ & $x$ & & $\mathrm{CH}$ \\
\hline Phacelia pinnatifida Griseb. ex Wedd. & Boraginaceae & $x$ & & & & & $\mathrm{Hpc}$ & & $x$ & & A \\
\hline Descurainia erodiifolia (Phil.) Prantl ex Reiche & Brassicaceae & $x$ & & $x$ & & & $\mathrm{Ha}$ & $x$ & & & MB \\
\hline $\begin{array}{l}\text { Exhalimolobos weddellii (E. Fourn.) Al- } \\
\text { Shehbaz \& C.D. Bley }\end{array}$ & Brassicaceae & $\mathrm{x}$ & & & & & $\mathrm{Ha}$ & $\mathrm{x}$ & & & $A B$ \\
\hline Lepidium bonariense L. & Brassicaceae & $x$ & & & & & $\mathrm{Hpc}$ & $x$ & & & $\mathrm{CH}$ \\
\hline $\begin{array}{l}\text { Mostacillastrum stenophyllum (Gillies ex } \\
\text { Hook. \& Arn. ) O.E. Schulz }\end{array}$ & Brassicaceae & $\mathrm{x}$ & & $x$ & & & Hps & $\mathrm{x}$ & & & $A B$ \\
\hline Deuterocohnia longipetala (Baker) Mez & Bromeliaceae & $x$ & & & & & $\mathrm{Br}$ & $x$ & & & $\mathrm{CH}$ \\
\hline Dyckia floribunda Griseb. var. floribunda & Bromeliaceae & $x$ & & $x$ & & & $\mathrm{Br}$ & $x$ & & & A \\
\hline Tillandsia bandensis Baker & Bromeliaceae & $x$ & & & & & $\mathrm{Ep}$ & $x$ & $x$ & & $A B$ \\
\hline Tillandsia capillaris Ruiz \& Pav. & Bromeliaceae & $x$ & & & & & Ep & $x$ & $x$ & & $A B$ \\
\hline Tillandsia pedicellata (Mez.) A. Cast. & Bromeliaceae & $x$ & & & & & $\mathrm{Ep}$ & & $x$ & & $A B$ \\
\hline Cereus aethiops Haw. & Cactaceae & $x$ & & & & & $\mathrm{Cc}$ & $x$ & $x$ & & $\mathrm{CH}$ \\
\hline Echinopsis aurea Britton \& Rose var. aurea & Cactaceae & $\mathrm{x}$ & & & $\mathrm{x}$ & & $\mathrm{Cg}$ & $\mathrm{x}$ & $\mathrm{x}$ & & $\mathrm{CH}$ \\
\hline $\begin{array}{l}\text { Gymnocalycium bruchii (Speg.) Hosseus var. } \\
\text { bruchii }\end{array}$ & Cactaceae & $x$ & & & & $x$ & $\mathrm{Cg}$ & $x$ & $x$ & & $\mathrm{CH}$ \\
\hline Gymnocalycium calochalorum (Boed.) Y. Ito & Cactaceae & $x$ & & & & $x$ & $\mathrm{Cg}$ & $x$ & & & $\mathrm{CH}$ \\
\hline Gymnocalycium erinaceum J.G. Lamb. & Cactaceae & $x$ & & & & $x$ & $\mathrm{Cg}$ & & $x$ & & $\mathrm{CH}$ \\
\hline $\begin{array}{l}\text { Gymnocalycium ochoterenae Backeb ssp. } \\
\text { ochoterenae }\end{array}$ & Cactaceae & $x$ & & & & $x$ & $\mathrm{Cg}$ & & $x$ & & $\mathrm{CH}$ \\
\hline $\begin{array}{l}\text { Harrisia pomanensis (F.A.C. Weber ex K. } \\
\text { Schaum.) Britton \& Rose ssp. pomanensis }\end{array}$ & Cactaceae & $x$ & & & & & $\mathrm{Cc}$ & $x$ & & & $\mathrm{CH}$ \\
\hline Opuntia salmiana Parm. & Cactaceae & $\mathrm{x}$ & & & & & Co & $\mathrm{x}$ & $\mathrm{x}$ & & $\mathrm{CH}$ \\
\hline
\end{tabular}




\begin{tabular}{|c|c|c|c|c|c|c|c|c|c|c|}
\hline \multirow{3}{*}{ Especie } & \multirow{3}{*}{ Familia } & \multirow{3}{*}{ Nat } & \multicolumn{3}{|c|}{ Status } & \multirow{3}{*}{ FdV } & \multirow{2}{*}{\multicolumn{3}{|c|}{ Afloramientos }} & \multirow{3}{*}{ C } \\
\hline & & & \multirow{2}{*}{ Exo } & \multicolumn{2}{|c|}{ Endemica } & & & & & \\
\hline & & & & $\mathbf{N} \mathbf{R}$ & $\mathbf{L}$ & & IR & MN & MA & \\
\hline $\begin{array}{l}\text { Opuntia sulphurea Gillies ex Salm-Dyck var. } \\
\text { sulphurea }\end{array}$ & Cactaceae & $\mathrm{x}$ & & & & Co & $\mathrm{x}$ & $\mathrm{x}$ & & $\mathrm{CH}$ \\
\hline $\begin{array}{l}\text { Trichocereus candicans (Gillies ex Salm- } \\
\text { Dyck) Britton \& Rose }\end{array}$ & Cactaceae & $\mathrm{x}$ & & $\mathrm{x}$ & & Cc & $\mathrm{x}$ & $\mathrm{x}$ & & $\mathrm{CH}$ \\
\hline Wahlenbergia linarioides (Lam.) A. DC. & Campanulaceae & $\mathrm{x}$ & & & & $\mathrm{Hpc}$ & & $\mathrm{x}$ & & $\mathrm{CH}$ \\
\hline $\begin{array}{l}\text { Cleome aculeata L. var. cordobensis (Eichler } \\
\text { \& Griseb.) Kuntze }\end{array}$ & Capparaceae & $\mathrm{x}$ & & & & $\mathrm{Hpc}$ & $\mathrm{x}$ & $\mathrm{x}$ & & $A B$ \\
\hline $\begin{array}{l}\text { Cardionema ramosissima (Weinm.) A. Nelson } \\
\text { \& J.F. Macbr. }\end{array}$ & Caryophyllaceae & $x$ & & & & Hps & $x$ & & & $A B$ \\
\hline Paronychia brasiliana DC. var. brasiliana & Caryophyllaceae & $x$ & & & & Hps & $\mathrm{X}$ & & & $A B$ \\
\hline Silene argentina (Pax) Bocquet & Caryophyllaceae & $\mathrm{x}$ & & $x$ & & $\mathrm{Hpc}$ & $x$ & $\mathrm{x}$ & & $\mathrm{CH}$ \\
\hline $\begin{array}{l}\text { Spergula ramosa (Cambess.) D. Dietr. ssp. } \\
\text { ramosa }\end{array}$ & Caryophyllaceae & $\mathrm{x}$ & & & & $\mathrm{Hpc}$ & $\mathrm{x}$ & & & $\mathrm{CH}$ \\
\hline $\begin{array}{l}\text { Celtis ehrenbergiana (Klotzsch) Liebm. var. } \\
\text { ehrenbergiana }\end{array}$ & Celtidaceae & $x$ & & & & A & $\mathrm{x}$ & $\mathrm{x}$ & & $\mathrm{CH}$ \\
\hline Jodina rhombifolia (Hook. \& Arn.) Reissek & Cervantesiaceae & $x$ & & & & A & $x$ & & & $A B$ \\
\hline Chenopodium album L. & Chenopodiaceae & & $x$ & & & $\mathrm{Ha}$ & $\mathrm{x}$ & $x$ & $x$ & $\mathrm{E}$ \\
\hline $\begin{array}{l}\text { Commelina erecta L. var. angustifolia (Michx.) } \\
\text { Fernald }\end{array}$ & Commelinaceae & $x$ & & & & Hps & $x$ & $x$ & $x$ & $A B$ \\
\hline Dichondra microcalyx (Hallier f.) Fabris & Convolvulaceae & $x$ & & & & Hps & $x$ & $x$ & & $\mathrm{CH}$ \\
\hline Dichondra sericea Sw. var. sericea & Convolvulaceae & $x$ & & & & Hps & $\mathrm{X}$ & $x$ & $x$ & $\mathrm{CH}$ \\
\hline Evolvulus sericeus Sw. var. sericeus & Convolvulaceae & $x$ & & & & Hps & $x$ & $x$ & $x$ & $\mathrm{CH}$ \\
\hline Ipomoea nil (L.) Roth & Convolvulaceae & $x$ & & & & En & & $x$ & & $A B$ \\
\hline Ipomoea purpurea (L.) Roth & Convolvulaceae & $x$ & & & & En & & $x$ & $x$ & $A B$ \\
\hline Ipomoea rubriflora O'Donell & Convolvulaceae & $\mathrm{x}$ & & & & En & & & $\mathrm{x}$ & $A B$ \\
\hline $\begin{array}{l}\text { Apodanthera sagittifolia (Griseb.) Mart.Crov. } \\
\text { var. sagittifolia }\end{array}$ & Cucurbitaceae & $x$ & & & & En & $x$ & & & MB \\
\hline $\begin{array}{l}\text { Cucurbitella asperata (Gillies ex Hook. \& Arn.) } \\
\text { Walp. }\end{array}$ & Cucurbitaceae & $\mathrm{x}$ & & & & $\mathrm{Hpc}$ & $\mathrm{x}$ & & & $A B$ \\
\hline Carex trachycystis Griseb. & Cyperaceae & $x$ & & & & $\mathrm{Gr}$ & $\mathrm{x}$ & & & $\mathrm{CH}$ \\
\hline $\begin{array}{l}\text { Cyperus aggregatus (Willd.) Endl. var. } \\
\text { aggregatus }\end{array}$ & Cyperaceae & $\mathrm{x}$ & & & & $\mathrm{Gr}$ & $x$ & $x$ & $x$ & $A B$ \\
\hline Cyperus esculentus L. var. esculentus & Cyperaceae & & $x$ & & & $\mathrm{Gr}$ & & & $x$ & $A B$ \\
\hline Cyperus rotundus $\mathrm{L}$. & Cyperaceae & & $x$ & & & $\mathrm{Gr}$ & & & $x$ & $A B$ \\
\hline Ephedra triandra Tul. emend. J.H. Hunz. & Ephedraceae & $x$ & & & & $\mathrm{Ar}$ & $\mathrm{x}$ & $x$ & & $A B$ \\
\hline Acalypha communis Müll. Arg. & Euphorbiaceae & $x$ & & & & Hps & $\mathrm{x}$ & $x$ & & $\mathrm{CH}$ \\
\hline Acalypha poiretii Spreng. & Euphorbiaceae & $\mathrm{x}$ & & & & $\mathrm{Ha}$ & & $x$ & & $\mathrm{CH}$ \\
\hline Croton hirtus L'Hér. & Euphorbiaceae & $x$ & & & & $\mathrm{Ha}$ & & $x$ & & $\mathrm{CH}$ \\
\hline Croton lachnostachyus Baill. & Euphorbiaceae & $x$ & & & & Hps & $x$ & $x$ & & $\mathrm{CH}$ \\
\hline Croton subpannosus Müll. Arg. ex Griseb. & Euphorbiaceae & $\mathrm{x}$ & & & & Hps & $\mathrm{x}$ & $x$ & & $\mathrm{CH}$ \\
\hline Euphorbia dentata Michx. & Euphorbiaceae & $\mathrm{x}$ & & & & $\mathrm{Ha}$ & $x$ & $\mathrm{x}$ & & $\mathrm{CH}$ \\
\hline
\end{tabular}




\begin{tabular}{|c|c|c|c|c|c|c|c|c|c|c|}
\hline \multirow{3}{*}{ Especie } & \multirow{3}{*}{ Familia } & \multirow{3}{*}{ Nat } & \multicolumn{3}{|c|}{ Status } & \multirow{3}{*}{ FdV } & \multirow{2}{*}{\multicolumn{3}{|c|}{ Afloramientos }} & \multirow{3}{*}{ C } \\
\hline & & & \multirow{2}{*}{ Exo } & \multicolumn{2}{|c|}{ Endemica } & & & & & \\
\hline & & & & $\mathbf{N}$ & $\mathbf{R} \quad \mathbf{L}$ & & IR & MN & MA & \\
\hline Euphorbia hirta L. var. hirta & Euphorbiaceae & & $x$ & & & $\mathrm{Hpc}$ & & $x$ & $x$ & $\mathrm{E}$ \\
\hline Euphorbia hypericifolia L. & Euphorbiaceae & $x$ & & & & $\mathrm{Hpc}$ & $x$ & & & $\mathrm{CH}$ \\
\hline Euphorbia hyssopifolia L. & Euphorbiaceae & $x$ & & & & $\mathrm{Hpc}$ & $x$ & & & $\mathrm{CH}$ \\
\hline Euphorbia serpens Kunth var. serpens & Euphorbiaceae & $x$ & & & & Hps & $x$ & & $x$ & $\mathrm{CH}$ \\
\hline Tragia geraniifolia Klotzsch ex Bll. & Euphorbiaceae & $x$ & & & & Hps & $x$ & $x$ & & $\mathrm{CH}$ \\
\hline Tragia volubilis $\mathrm{L}$. & Euphorbiaceae & $x$ & & & & En & $x$ & & & $\mathrm{CH}$ \\
\hline Acacia caven (Molina) Molina var. caven & Fabaceae & $x$ & & & & A & $x$ & $x$ & $x$ & $\mathrm{CH}$ \\
\hline Acacia praecox Griseb. & Fabaceae & $\mathrm{x}$ & & & & A & $x$ & & & $\mathrm{CH}$ \\
\hline Cologania broussonetii (Balb.) DC. & Fabaceae & $x$ & & & & $\mathrm{Hpc}$ & & $\mathrm{x}$ & & $\mathrm{CH}$ \\
\hline Galactia glaucophylla Harms & Fabaceae & $x$ & & & $x$ & Hps & $x$ & $\mathrm{x}$ & & $A B$ \\
\hline Galactia latisiliqua Desv. & Fabaceae & $x$ & & & & Hps & $x$ & $x$ & & $A B$ \\
\hline $\begin{array}{l}\text { Geoffroea decorticans (Gillies ex Hook. \& } \\
\text { Arn.) Burkart }\end{array}$ & Fabaceae & $x$ & & & & A & $x$ & $x$ & & $A B$ \\
\hline Gleditsia triacanthos L. & Fabaceae & & $x$ & & & A & & & $x$ & $\mathrm{E}$ \\
\hline Rhynchosia bicentrica B.L. Turner & Fabaceae & $x$ & & & & Hps & $x$ & & & $A B$ \\
\hline Rhynchosia senna Gillies ex Hook. var. senna & Fabaceae & $x$ & & & & Hps & $x$ & & & $A B$ \\
\hline Senna morongii (Britton) H.S. Irwin \& Barneby & Fabaceae & $x$ & & & & $\mathrm{Hpc}$ & $x$ & & & $\mathrm{CH}$ \\
\hline Zornia trachycarpa Vogel & Fabaceae & $x$ & & & & $\mathrm{Hpc}$ & $x$ & & & $\mathrm{CH}$ \\
\hline $\begin{array}{l}\text { Cantinoa mutabilis (Rich. Harley \& J.F.B. } \\
\text { Pastore }\end{array}$ & Lamiaceae & $x$ & & & & Hps & $x$ & $\mathrm{x}$ & & $A B$ \\
\hline Lepechinia floribunda (Benth.) Epling & Lamiaceae & $x$ & & & & Hps & $x$ & $x$ & & $\mathrm{CH}$ \\
\hline Minthostachys verticillata (Griseb.) Epling & Lamiaceae & $x$ & & $x$ & & Hps & $x$ & & & $\mathrm{CH}$ \\
\hline $\begin{array}{l}\text { Salvia cuspidata Ruiz \& Pav. ssp. gilliesii } \\
\text { (Benth.) J.R.I. Wood }\end{array}$ & Lamiaceae & $x$ & & & & $\mathrm{Ar}$ & $x$ & $\mathrm{x}$ & & $\mathrm{CH}$ \\
\hline Mentzelia albescens (Gillies ex Arn.) Griseb. & Loasaceae & $x$ & & & & $\mathrm{Hpc}$ & $x$ & $\mathrm{x}$ & & $\mathrm{CH}$ \\
\hline Ligaria cuneifolia (Ruiz \& Pav.) Tiegh. & Loranthaceae & $x$ & & & & $\mathrm{P}$ & $x$ & & & $A B$ \\
\hline $\begin{array}{l}\text { Tripodanthus flagellaris (Cham. \& Schltdl. } \\
\text { Tiegh. }\end{array}$ & Loranthaceae & $x$ & & & & $P$ & $x$ & & & $\mathrm{CH}$ \\
\hline Cuphea glutinosa Cham. \& Schltdl. & Lythraceae & $x$ & & & & Hps & & $x$ & & MB \\
\hline Heimia salicifolia (Kunth) Link & Lythraceae & $x$ & & & & $\mathrm{Ar}$ & & $x$ & & $A B$ \\
\hline Cordobia argentea (Griseb.) Nied. & Malpighiaceae & $x$ & & & & Hps & $x$ & & & $\mathrm{CH}$ \\
\hline Janusia guaranitica (A. St.-Hil.) A. Juss. & Malpighiaceae & $x$ & & & & En & $x$ & $x$ & & MB \\
\hline Abutilon pauciflorum A. St.-Hil. & Malvaceae & $x$ & & & & $\mathrm{Ar}$ & $x$ & $x$ & & $\mathrm{CH}$ \\
\hline Anoda cristata (L.) Schltdl. & Malvaceae & $x$ & & & & $\mathrm{Ha}$ & & & $x$ & $A B$ \\
\hline Gaya parviflora (Phil.) Krapov. & Malvaceae & $x$ & & & & $\mathrm{Hpc}$ & $x$ & $\mathrm{x}$ & & $A B$ \\
\hline Herissantia crispa (L.) Brizicky & Malvaceae & $x$ & & & & Hps & $x$ & $x$ & & $\mathrm{CH}$ \\
\hline Krapovickasia flavescens (Cav.) Fryxell & Malvaceae & $x$ & & & & Hps & $x$ & $\mathrm{x}$ & & $\mathrm{CH}$ \\
\hline
\end{tabular}




\begin{tabular}{|c|c|c|c|c|c|c|c|c|c|c|}
\hline \multirow{3}{*}{ Especie } & \multirow{3}{*}{ Familia } & \multirow{3}{*}{ Nat } & \multicolumn{3}{|c|}{ Status } & \multirow{3}{*}{ FdV } & \multirow{2}{*}{\multicolumn{3}{|c|}{ Afloramientos }} & \multirow{3}{*}{ C } \\
\hline & & & \multirow{2}{*}{ Exo } & \multicolumn{2}{|c|}{ Endemica } & & & & & \\
\hline & & & & $\mathbf{N} \mathbf{R}$ & $\mathbf{L}$ & & IR & MN & MA & \\
\hline $\begin{array}{l}\text { Malvastrum coromandelianum (L.) Garcke } \\
\text { ssp. coromandelianum }\end{array}$ & Malvaceae & $x$ & & & & $\mathrm{Hpc}$ & $x$ & $x$ & & $\mathrm{CH}$ \\
\hline Pavonia aurigloba Krapov. \& Cristóbal & Malvaceae & $x$ & & & & Hps & & $x$ & & $A B$ \\
\hline Pseudabutilon virgatum (Cav. )Fryxell & Malvaceae & $x$ & & & & Hps & $x$ & & & $\mathrm{CH}$ \\
\hline Rhynchosida physocalyx (A. Gray) Fryxell & Malvaceae & $x$ & & & & Hps & $x$ & $\mathrm{x}$ & & $\mathrm{CH}$ \\
\hline Sida argentina K. Schum. var. argentina & Malvaceae & $\mathrm{x}$ & & & & Hps & $\mathrm{x}$ & $\mathrm{x}$ & & $A B$ \\
\hline Sida dictyocarpa Griseb. ex K. Schum. & Malvaceae & $x$ & & & & $\mathrm{Hpc}$ & $x$ & $x$ & & $\mathrm{CH}$ \\
\hline Sida rhombifolia L. & Malvaceae & $\mathrm{x}$ & & & & $\mathrm{Hpc}$ & $\mathrm{x}$ & $x$ & & $\mathrm{CH}$ \\
\hline Sida spinosa L. & Malvaceae & $x$ & & & & $\mathrm{Hpc}$ & $x$ & $\mathrm{x}$ & & $\mathrm{CH}$ \\
\hline Sphaeralcea cordobensis Krapov. & Malvaceae & $\mathrm{x}$ & & $\mathrm{x}$ & & $\mathrm{Hpc}$ & $\mathrm{x}$ & & $\mathrm{x}$ & $\mathrm{CH}$ \\
\hline $\begin{array}{l}\text { Wissadula gymnanthemum (Griseb.) K. } \\
\text { Schum. }\end{array}$ & Malvaceae & $x$ & & & & $\mathrm{Hpc}$ & $\mathrm{x}$ & $x$ & & $\mathrm{CH}$ \\
\hline Mollugo verticillata $\mathrm{L}$. & Molluginaceae & & $\mathrm{x}$ & & & $\mathrm{Ha}$ & & $x$ & & $\mathrm{E}$ \\
\hline Boerhavia diffusa L. var. diffusa & Nyctaginaceae & $\mathrm{x}$ & & & & $\mathrm{Hpc}$ & $\mathrm{x}$ & $\mathrm{x}$ & & $A B$ \\
\hline $\begin{array}{l}\text { Menodora integrifolia (Cham. \& Schaltdl.) } \\
\text { Steud. var. integrifolia }\end{array}$ & Oleaceae & $x$ & & & & Hps & $\mathrm{x}$ & & & $\mathrm{CH}$ \\
\hline Sacoila lanceolata (Aubl.) Garay & Orchidaceae & $x$ & & & & $\mathrm{Hpc}$ & $x$ & & & $\mathrm{CH}$ \\
\hline Oxalis articulata Savign & Oxalidaceae & & $x$ & & & $\mathrm{Hpc}$ & & & $\mathrm{x}$ & $A B$ \\
\hline Oxalis conorrhiza Jacq. & Oxalidaceae & $x$ & & & & $\mathrm{Hpc}$ & $\mathrm{x}$ & $x$ & $x$ & $A B$ \\
\hline Passiflora foetida L. var. foetida & Passifloraceae & $x$ & & & & En & $x$ & $x$ & & MB \\
\hline Rivina humilis $\mathrm{L}$. & Phytolaccaceae & $x$ & & & & Hps & $x$ & $x$ & & $\mathrm{CH}$ \\
\hline Plantago tomentosa Lam. ssp. tomentosa & Plantaginaceae & $x$ & & & & $\mathrm{Hpc}$ & $\mathrm{x}$ & & & $A B$ \\
\hline Plumbago caerulea Kunth & Plumbaginaceae & $x$ & & & & Hps & $\mathrm{x}$ & $x$ & & $\mathrm{CH}$ \\
\hline Aristida mendocina Phil. & Poaceae & $x$ & & & & G & & $x$ & & $\mathrm{CH}$ \\
\hline Bothriochloa barbinodis (Lag.) Herter & Poaceae & $x$ & & & & $\mathrm{Gm}$ & $x$ & $x$ & & $A B$ \\
\hline Bouteloua megapotamica (Spreng.) Kuntze & Poaceae & $x$ & & & & $\mathrm{Gr}$ & $x$ & $x$ & & $\mathrm{CH}$ \\
\hline Briza maxima L. & Poaceae & $\mathrm{x}$ & & & & $\mathrm{Gm}$ & $\mathrm{x}$ & & & MB \\
\hline Bromus auleticus Trin. ex Nees & Poaceae & $x$ & & & & $\mathrm{Gm}$ & $\mathrm{x}$ & & & MB \\
\hline Bromus catharticus Vahl var. catharticus & Poaceae & $x$ & & & & G & & & $x$ & MB \\
\hline $\begin{array}{l}\text { Cenchrus myosuroides Kunth var. } \\
\text { myosuroides }\end{array}$ & Poaceae & $x$ & & & & G & & $x$ & & $A B$ \\
\hline Cenchrus spinifex Cav. & Poaceae & $x$ & & & & G & & & $x$ & $A B$ \\
\hline Chloris ciliata Sw. fo. ciliata & Poaceae & $x$ & & & & G & & $x$ & $x$ & $A B$ \\
\hline Chloris virgata Sw. & Poaceae & $x$ & & & & G & & & $x$ & $A B$ \\
\hline Cynodon dactylon (L.) Pers. var. dactylon & Poaceae & & $x$ & & & G & & & $x$ & CMP \\
\hline $\begin{array}{l}\text { Digitaria californica (Benth.) Henrard var. } \\
\text { californica }\end{array}$ & Poaceae & $x$ & & & & G & $x$ & $\mathrm{x}$ & & $A B$ \\
\hline Digitaria sanguinalis (L.) Scop. & Poaceae & & $\mathrm{x}$ & & & G & & & $\mathrm{x}$ & $\mathrm{E}$ \\
\hline
\end{tabular}




\begin{tabular}{|c|c|c|c|c|c|c|c|c|c|c|}
\hline \multirow{3}{*}{ Especie } & \multirow{3}{*}{ Familia } & \multirow{3}{*}{ Nat } & \multicolumn{3}{|c|}{ Status } & \multirow{3}{*}{ FdV } & \multirow{2}{*}{\multicolumn{3}{|c|}{ Afloramientos }} & \multirow{3}{*}{ C } \\
\hline & & & \multirow{2}{*}{ Exo } & \multicolumn{2}{|c|}{ Endemica } & & & & & \\
\hline & & & & $\mathbf{N} \mathbf{R}$ & $\mathbf{L}$ & & IR & MN & MA & \\
\hline Echinochloa colona (L.) Link & Poaceae & & $x$ & & & G & & & $x$ & CMP \\
\hline Eleusine indica (L.) Gaertn. & Poaceae & & $\mathrm{x}$ & & & G & & & $x$ & $E$ \\
\hline Eragrostis cilianensis (All.) Vignolo ex Janch & Poaceae & & $x$ & & & G & & & $x$ & $E$ \\
\hline Eragrostis lugens Nees & Poaceae & $x$ & & & & $\mathrm{Gm}$ & $x$ & $\mathrm{x}$ & $x$ & $A B$ \\
\hline Eustachys distichophylla (Lag). Nees & Poaceae & $x$ & & & & $\mathrm{Gm}$ & $x$ & & & $A B$ \\
\hline Eustachys retusa (Lag.) Kunth & Poaceae & $x$ & & & & G & & $x$ & $\mathrm{x}$ & $\mathrm{CH}$ \\
\hline Gouinia latifolia (Griseb.) Vasey & Poaceae & $x$ & & & & $\mathrm{Gm}$ & $x$ & $x$ & & MB \\
\hline $\begin{array}{l}\text { Gouinia paraguayensis (Kuntze) Parodi var. } \\
\text { paraguayensis }\end{array}$ & Poaceae & $x$ & & & & $\mathrm{Gm}$ & & $\mathrm{x}$ & & $\mathrm{MB}$ \\
\hline Gymnopogon spicatus (Spreng.) Kuntze & Poaceae & $x$ & & $x$ & & G & $x$ & & & $\mathrm{CH}$ \\
\hline $\begin{array}{l}\text { Heteropogon contortus (L.) P. Beauv. ex } \\
\text { Roem. \& Schult. }\end{array}$ & Poaceae & $x$ & & & & G & $x$ & $x$ & & $\mathrm{CH}$ \\
\hline Jarava ichu Ruiz \& Pav. var. ichu & Poaceae & $x$ & & & & $\mathrm{Gm}$ & $x$ & $x$ & & $\mathrm{CH}$ \\
\hline Melica argyrea Hack. & Poaceae & $x$ & & & & $\mathrm{Gm}$ & $x$ & & & $A B$ \\
\hline Melica eremophila Torres & Poaceae & $x$ & & & & $\mathrm{Gm}$ & $x$ & & & $A B$ \\
\hline Melinis repens (Willd.) Zizka & Poaceae & & $x$ & & & G & $x$ & $x$ & & $\mathrm{E}$ \\
\hline Nassella cordobensis (Speg.) Barkworth & Poaceae & $x$ & & $x$ & & $\mathrm{Gm}$ & $x$ & $x$ & & $\mathrm{MB}$ \\
\hline Nassella filiculmis (Delile) Barkworth & Poaceae & $x$ & & & & $\mathrm{Gm}$ & $x$ & & & MB \\
\hline Nassella hyalina (Nees) Barkworth & Poaceae & $x$ & & & & $\mathrm{Gm}$ & $x$ & & & MB \\
\hline Nassella neesiana (Trin. \& Rupr.) Barkworth & Poaceae & $x$ & & & & $\mathrm{Gm}$ & $x$ & & & MB \\
\hline Nassella tenuissima (Trin) Barkworth & Poaceae & $x$ & & $x$ & & $\mathrm{Gm}$ & & & $x$ & A \\
\hline Pappophorum phillippianum Parodi & Poaceae & $x$ & & $x$ & & $\mathrm{Gm}$ & $x$ & $x$ & & $\mathrm{CH}$ \\
\hline Paspalum humboldtianum Flüggé & Poaceae & $x$ & & & & $\mathrm{Gm}$ & $x$ & $\mathrm{x}$ & & $\mathrm{MB}$ \\
\hline Paspalum malacophyllum Trin. & Poaceae & $x$ & & & & $\mathrm{Gm}$ & $x$ & $x$ & & $\mathrm{MB}$ \\
\hline Paspalum notatum Flüggé & Poaceae & $x$ & & & & G & & $x$ & & $A B$ \\
\hline $\begin{array}{l}\text { Piptochaetium montevidense (Spreng.) } \\
\text { Parodi }\end{array}$ & Poaceae & $x$ & & & & $\mathrm{Gm}$ & $x$ & $x$ & & $\mathrm{CH}$ \\
\hline $\begin{array}{l}\text { Poa ligularis Nees ex Steud. var. resinulosa } \\
\text { (Nees ex Steud.) Fernández Pepi \& Giussani }\end{array}$ & Poaceae & $x$ & & $x$ & & $\mathrm{Gm}$ & $x$ & & & $A B$ \\
\hline Schizachyrium spicatum (Spreng.) Herter & Poaceae & $x$ & & & & $\mathrm{Gm}$ & $x$ & $x$ & & $A B$ \\
\hline Setaria cordobensis R.A.W. Herrm. & Poaceae & $x$ & & $x$ & & $\mathrm{Gm}$ & $x$ & $x$ & & $\mathrm{CH}$ \\
\hline Setaria lachnea (Nees) Kunth & Poaceae & $x$ & & & & $\mathrm{Gm}$ & $x$ & $x$ & & $\mathrm{CH}$ \\
\hline Setaria leucopila (Scribn. \& Merr. ) K. Schum. & Poaceae & $x$ & & & & $\mathrm{Gm}$ & $x$ & $x$ & & $\mathrm{CH}$ \\
\hline $\begin{array}{l}\text { Setaria parviflora (Poir.) Kerguélen var. } \\
\text { parviflora }\end{array}$ & Poaceae & $x$ & & & & $\mathrm{Gm}$ & $x$ & $x$ & & $A B$ \\
\hline Sorghum halepense (L.) Pers. & Poaceae & & $x$ & & & $\mathrm{Gm}$ & & & $x$ & $E$ \\
\hline Tragus australianus Blake & Poaceae & & $x$ & & & G & & $\mathrm{x}$ & & $\mathrm{E}$ \\
\hline Monnina dictyocarpa Griseb. & Polygalaceae & $x$ & & & & Hps & $x$ & & & $\mathrm{MB}$ \\
\hline
\end{tabular}




\begin{tabular}{|c|c|c|c|c|c|c|c|c|c|c|}
\hline \multirow{3}{*}{ Especie } & \multirow{3}{*}{ Familia } & \multirow{3}{*}{ Nat } & \multicolumn{3}{|c|}{ Status } & \multirow{3}{*}{ FdV } & \multirow{2}{*}{\multicolumn{3}{|c|}{ Afloramientos }} & \multirow{3}{*}{ C } \\
\hline & & & \multirow{2}{*}{ Exo } & \multicolumn{2}{|c|}{ Endemica } & & & & & \\
\hline & & & & $\mathbf{N} \mathbf{R}$ & $\mathbf{R} \quad \mathbf{L}$ & & IR & MN & MA & \\
\hline Polygala stenophylla A. Gray & Polygalaceae & $x$ & & $x$ & & Hps & $x$ & & & $A$ \\
\hline Pleopeltis pinnatifida Gillies ex Hook. \& Grev. & Polypodiaceae & $x$ & & & & $\mathrm{H}$ & $x$ & & & A \\
\hline Portulaca obtusa Poelln. & Portulacaceae & $x$ & & $x$ & & $\mathrm{Hpc}$ & $x$ & $x$ & & $\mathrm{CH}$ \\
\hline Portulaca oleracea L. & Portulacaceae & & $x$ & & & $\mathrm{Ha}$ & & & $x$ & $E$ \\
\hline $\begin{array}{l}\text { Argyrochosma nivea (Poir. Windham var. } \\
\text { nivea }\end{array}$ & Pteridaceae & $x$ & & & & $\mathrm{H}$ & $x$ & & & MB \\
\hline Cheilanthes buchtienii (Rosenst.) R.M. Tryon & Pteridaceae & $x$ & & & & $\mathrm{H}$ & $x$ & $x$ & & $A$ \\
\hline Cheilanthes micropteris Sw. & Pteridaceae & $x$ & & & & $\mathrm{H}$ & $x$ & & & $A$ \\
\hline Cheilanthes myriophylla Desv. & Pteridaceae & $x$ & & & & $\mathrm{H}$ & $x$ & & & $A$ \\
\hline $\begin{array}{l}\text { Clematis montevidensis Spreng. var. } \\
\text { montevidensis }\end{array}$ & Ranunculaceae & $x$ & & & & En & $x$ & $x$ & $x$ & $A B$ \\
\hline Colletia spinosissima J.F. Gmel. & Rhamnaceae & $x$ & & & & $\operatorname{Ar}$ & $x$ & $x$ & & MB \\
\hline Condalia microphylla Cav. & Rhamnaceae & $x$ & & $x$ & & A & $x$ & $x$ & & $\mathrm{CH}$ \\
\hline Kageneckia lanceolata Ruiz \& Pav & Rosaceae & $x$ & & & & A & $x$ & $x$ & & MB \\
\hline $\begin{array}{l}\text { Borreria eryngioides Cham. \& SChltdl. var. } \\
\text { eryngioides }\end{array}$ & Rubiaceae & $x$ & & $x$ & & Hps & & $x$ & $x$ & $A B$ \\
\hline Borreria spinosa (L.) Cham. \& SChltdl. & Rubiaceae & $x$ & & & & Hps & & & $x$ & $A B$ \\
\hline $\begin{array}{l}\text { Galium richardianum (Gillies ex Hook. \& Arn.) } \\
\text { Endl. ex Walp. ssp. richardianum }\end{array}$ & Rubiaceae & $x$ & & & & $\mathrm{Ha}$ & $x$ & $x$ & $x$ & $\mathrm{CH}$ \\
\hline Mitracarpus megapotamicus (Spreng.) Kuntze & Rubiaceae & $x$ & & & & Hps & $x$ & $x$ & $x$ & $A B$ \\
\hline $\begin{array}{l}\text { Cardiospermum halicacabum L. var. } \\
\text { halicacabum }\end{array}$ & Sapindaceae & $x$ & & & & En & $x$ & $x$ & & $\mathrm{CH}$ \\
\hline $\begin{array}{l}\text { Anemia tomentosa (Savigny) Sw. var. } \\
\text { tomentosa }\end{array}$ & Schizaeaceae & $x$ & & & & $\mathrm{H}$ & $x$ & $x$ & & MB \\
\hline Buddleja cordobensis Griseb. & Scrophulariaceae & $x$ & & $x$ & & $\mathrm{Ar}$ & $x$ & & & $\mathrm{CH}$ \\
\hline Selaginella sellowii Hieron. & Selaginellaceae & $x$ & & & & $\mathrm{H}$ & $x$ & $x$ & & A \\
\hline Bouchetia anomala (Miers) Britton \& Rusby & Solanaceae & $x$ & & & & $\mathrm{Hpc}$ & $x$ & & & $A B$ \\
\hline Capsicum chacoense Hunz. & Solanaceae & $x$ & & & & Hps & $x$ & & & $\mathrm{CH}$ \\
\hline Cestrum parqui L'Hér. & Solanaceae & $x$ & & $x$ & & Hps & $x$ & $x$ & & $A B$ \\
\hline Datura ferox $\mathrm{L}$. & Solanaceae & & $x$ & & & $\mathrm{Ha}$ & & & $x$ & $A B$ \\
\hline Lycium chilense Miers ex Bertero var. chilense & Solanaceae & $x$ & & & & $\mathrm{Ar}$ & $x$ & $x$ & & MB \\
\hline $\begin{array}{l}\text { Nierembergia linariaefolia Gragham var. } \\
\text { linariaefolia }\end{array}$ & Solanaceae & $x$ & & & & Hps & & $x$ & & $A B$ \\
\hline $\begin{array}{l}\text { Petunia axillaris (Lam.) Britton, Stern \& } \\
\text { Poggenb. ssp. axillaris }\end{array}$ & Solanaceae & $x$ & & & & $\mathrm{Hpc}$ & $x$ & & & $A B$ \\
\hline Salpichroa origanifolia (Lam.) Blaill. & Solanaceae & $x$ & & & & Hps & $x$ & $x$ & & $A B$ \\
\hline Solanum chacoensis Bitter & Solanaceae & $x$ & & & & Hps & & & $x$ & $A B$ \\
\hline Solanum elaeagnifolium Cav. & Solanaceae & $x$ & & & & Hps & $x$ & & & $A B$ \\
\hline Solanum hieronymi Kuntze & Solanaceae & $x$ & & & & $\mathrm{Hpc}$ & $x$ & $x$ & & $A B$ \\
\hline Solanum sarrachoides Sendtn. & Solanaceae & $x$ & & & & $\mathrm{Hpc}$ & $x$ & $x$ & & $A B$ \\
\hline
\end{tabular}




\section{J. J. Cantero et al. - Heterogeneidad de la vegetación en ambientes basálticos}

\begin{tabular}{|c|c|c|c|c|c|c|c|c|c|c|}
\hline \multirow{3}{*}{ Especie } & \multirow{3}{*}{ Familia } & \multirow{3}{*}{ Nat } & \multicolumn{3}{|c|}{ Status } & \multirow{3}{*}{ FdV } & \multirow{2}{*}{\multicolumn{3}{|c|}{ Afloramientos }} & \multirow{3}{*}{ C } \\
\hline & & & \multirow{2}{*}{ Exo } & \multicolumn{2}{|c|}{ Endemica } & & & & & \\
\hline & & & & N R & $\mathbf{L}$ & & IR & MN & MA & \\
\hline Solanum stuckertii Bitter & Solanaceae & $x$ & & & & Hps & $\mathrm{x}$ & $x$ & & $A B$ \\
\hline Melochia argentina R.E. Fr. & Sterculiaceae & $x$ & & & & $\mathrm{Hpc}$ & $x$ & $x$ & & $\mathrm{CH}$ \\
\hline Talinum paniculatum (Jacq.) Gaertn. & Talinaceae & $\mathrm{x}$ & & & & Hps & $x$ & $\mathrm{x}$ & $\mathrm{x}$ & $A B$ \\
\hline $\begin{array}{l}\text { Turnera sidoides L. ssp. pinnatifida (Juss. ex } \\
\text { Poir.) Arbo }\end{array}$ & Turneraceae & $x$ & & & & $\mathrm{Hpc}$ & $x$ & $x$ & & $A B$ \\
\hline Ulmus pumila L. & Ulmaceae & & $x$ & & & A & & & $x$ & $E$ \\
\hline Parietaria debilis G. Forst. & Urticaceae & $x$ & & & & $\mathrm{Ha}$ & $x$ & & $x$ & $\mathrm{CH}$ \\
\hline $\begin{array}{l}\text { Aloysia gratissima (Gillies \& Hook. ex Hook.) } \\
\text { Tronc. var. gratissima }\end{array}$ & Verbenaceae & $x$ & & & & $\mathrm{Ar}$ & $x$ & $x$ & & $\mathrm{CH}$ \\
\hline Glandularia peruviana (L.) Small & Verbenaceae & $\mathrm{x}$ & & & & $\mathrm{Hpc}$ & $\mathrm{x}$ & & & $A B$ \\
\hline $\begin{array}{l}\text { Glandularia platensis (Spreng.) Schnack \& } \\
\text { Covas }\end{array}$ & Verbenaceae & $\mathrm{x}$ & & & & $\mathrm{Hpc}$ & & $\mathrm{x}$ & & $A B$ \\
\hline $\begin{array}{l}\text { Glandularia pulchella Sweet (Troncoso) aff. } \\
\text { pulchella }\end{array}$ & Verbenaceae & $x$ & & & & $\mathrm{Hpc}$ & & & $x$ & $A B$ \\
\hline Glandularia subincana Tronc. & Verbenaceae & $\mathrm{x}$ & & & & $\mathrm{Hpc}$ & $x$ & & & $A B$ \\
\hline Glandularia tenera (Spreng.) Cabrera & Verbenaceae & $x$ & & & & $\mathrm{Hpc}$ & $\mathrm{x}$ & $x$ & & $A B$ \\
\hline Lantana balansae Briq. & Verbenaceae & $x$ & & & & $\mathrm{Ar}$ & $\mathrm{x}$ & $x$ & & $\mathrm{CH}$ \\
\hline Lantana fucata Lindl. & Verbenaceae & $x$ & & & & $\operatorname{Ar}$ & $x$ & $x$ & & $\mathrm{CH}$ \\
\hline Lantana megapotamica (Spreng.) Tronc. & Verbenaceae & $x$ & & & & $\operatorname{Ar}$ & $\mathrm{x}$ & $x$ & & $\mathrm{CH}$ \\
\hline Lippia integrifolia (Griseb.) Hieron. & Verbenaceae & $x$ & & & & $\operatorname{Ar}$ & $x$ & $x$ & & $\mathrm{CH}$ \\
\hline Lippia turbinata Griseb. f. turbinata & Verbenaceae & $x$ & & & & $\mathrm{Ar}$ & $\mathrm{x}$ & $x$ & & $\mathrm{CH}$ \\
\hline Pombalia parviflora (L. f.) Paula-Souza & Violaceae & $x$ & & & & Hps & & & $x$ & $A B$ \\
\hline Pombalia serrata (Phil.) Paula-Souza & Violaceae & $x$ & & $x$ & & Hps & $x$ & $x$ & & $A B$ \\
\hline Woodsia montevidensis (Spreng.) Hieron. & Woodsiaceae & $x$ & & & & $\mathrm{H}$ & $x$ & $\mathrm{x}$ & & A \\
\hline Ximenia americana L. var. americana & Ximeniaceae & $\mathrm{x}$ & & & & A & $\mathrm{x}$ & $\mathrm{x}$ & & $\mathrm{CH}$ \\
\hline $\begin{array}{l}\text { Porlieria microphylla (Baill.) Descole, O’Donell } \\
\text { \& Lourteig }\end{array}$ & Zygophyllaceae & $\mathrm{x}$ & & & & A & $x$ & $x$ & & $\mathrm{CH}$ \\
\hline
\end{tabular}

